\title{
Retrieval of optical and physical properties of African dust from multiwavelength Raman lidar measurements during the SHADOW campaign in Senegal
}

\author{
I. Veselovskii ${ }^{1,2}$, P. Goloub ${ }^{3}$, T. Podvin ${ }^{3}$, V. Bovchaliuk ${ }^{3}$, Y. Derimian ${ }^{3}$, P. Augustin ${ }^{4}$, M. Fourmentin ${ }^{4}$, D. Tanre ${ }^{3}$,

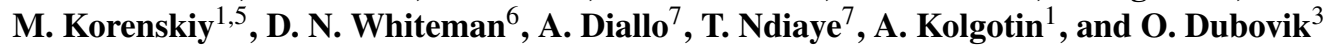 \\ ${ }^{1}$ Physics Instrumentation Center of GPI, Troitsk, Moscow, Russia \\ ${ }^{2}$ Joint Center for Earth Systems Technology, UMBC, Baltimore, MD, USA \\ ${ }^{3}$ Laboratoire d'Optique Atmosphérie, Université de Lille-CNRS, 59650, Villeneuve-d'Ascq, France \\ ${ }^{4}$ Laboratoire de Physico-chimie de l'atmosphère, Université du littoral côte d'Opale, Dunkerque, France \\ ${ }^{5}$ Far Eastern Federal University, Vladivostok, Russia \\ ${ }^{6}$ NASA GSFC, Greenbelt, MD, USA \\ ${ }^{7}$ Institut de Recherche pour le Développement, Dakar, Senegal
}

Correspondence to: I. Veselovskii (igorv@ pic.troitsk.ru)

Received: 2 February 2016 - Published in Atmos. Chem. Phys. Discuss.: 19 February 2016

Revised: 24 May 2016 - Accepted: 25 May 2016 - Published: 8 June 2016

\begin{abstract}
West Africa and the adjacent oceanic regions are very important locations for studying dust properties and their influence on weather and climate. The SHADOW (study of SaHAran Dust Over West Africa) campaign is performing a multiscale and multilaboratory study of aerosol properties and dynamics using a set of in situ and remote sensing instruments at an observation site located at the IRD (Institute for Research and Development) in Mbour, Senegal $\left(14^{\circ} \mathrm{N}, 17^{\circ} \mathrm{W}\right)$. In this paper, we present the results of lidar measurements performed during the first phase of SHADOW (study of SaHAran Dust Over West Africa) which occurred in March-April 2015. The multiwavelength Mie-Raman lidar acquired $3 \beta+2 \alpha+1 \delta$ measurements during this period. This set of measurements has permitted particle-intensive properties, such as extinction and backscattering Ångström exponents (BAE) for 355/532 nm wavelengths' corresponding lidar ratios and depolarization ratio at $532 \mathrm{~nm}$, to be determined. The mean values of dust lidar ratios during the observation period were about $53 \mathrm{sr}$ at both 532 and $355 \mathrm{~nm}$, which agrees with the values observed during the SAMUM-1 and SAMUM-2 campaigns held in Morocco and Cabo Verde in 2006 and 2008. The mean value of the particle depolarization ratio at $532 \mathrm{~nm}$ was $30 \pm 4.5 \%$; however, during strong dust episodes this ratio increased to $35 \pm 5 \%$, which is also
\end{abstract}

in agreement with the results of the SAMUM campaigns. The backscattering Ångström exponent during the dust episodes decreased to $\sim-0.7$, while the extinction Ångström exponent, though negative, was greater than -0.2 . Low values of BAE can likely be explained by an increase in the imaginary part of the dust refractive index at $355 \mathrm{~nm}$ compared to $532 \mathrm{~nm}$. The dust extinction and backscattering coefficients at multiple wavelengths were inverted to the particle microphysics using the regularization algorithm and the model of randomly oriented spheroids. The analysis performed has demonstrated that the spectral dependence of the imaginary part of the dust refractive index may significantly influence the inversion results and should be taken into account.

\section{Introduction}

The impact of desert dust emitted into atmosphere on the Earth's radiation budget is the subject of intense research (Sokolik and Toon, 1996; Balkanski et al., 2007; Mahowald et al., 2010; Formenti et al., 2011, 2014). Due to the wind patterns involved, dust can be transported far away from the main source regions in Africa and Asia, allowing it to be distributed in varying amounts all over the globe. North 
Africa is the largest source of dust in the world and several field campaigns have been conducted to evaluate dust particle microphysical properties over western Africa and to study long-range transport of Saharan dust (Reid and Maring, 2003; Tanre et al., 2003; Redelsperger et al., 2006; McConnell et al., 2008). During these campaigns, dust particles were studied via aircraft, ground sampling, and using sun photometer measurements. However, vertical distribution of dust has received little attention even though dust vertical structure is critical for an improved understanding of dust advection, transport and dust-cloud interactions. The commonly used instrument to evaluate the height profile of dust particle properties is the aerosol lidar. The numerous measurements performed in Europe, the US, and Asia with multiwavelength Raman and high spectral resolution lidar (HSRL) systems have resulted in a significant amount of information about the vertical distribution of dust-intensive properties, such as depolarization, lidar ratios, extinction, and backscattering Ångström exponents (Sakai et al., 2003; De Tomasi et al., 2003; Shimizu et al., 2004; Mona et al., 2006; Papayannis et al., 2008; Xie et al., 2008; Ansmann et al., 2012; Burton et al., 2014; Nisantzi et al., 2015). However, these measurements were mostly performed at a significant distance from the source area, so the dust particles were aged due to mixing with local aerosols and coating with soluble aerosol species (Li and Shao, 2009) and may not have well represented the characteristics of the dust upon initial emission.

To analyze the properties of pure dust, measurements near the source regions are needed. Such measurements of Saharan dust were performed during the SAMUM-1 and SAMUM-2 experiments using the assembly of Raman and HSRL lidars (Ansmann et al., 2011). During those measurements the dust episodes and more complicated events, when the dust and smoke layers occurred simultaneously, were studied (Tesche et al., 2009a, b, 2011; Esselborn et al., 2009). However, for the estimation of aerosol radiative forcing, not only the particle-intensive parameters but also their microphysical properties, such as size, concentration, and the complex refractive index (CRI) are needed. An estimation of the vertical distribution of particle microphysics can be achieved, for example, by combining lidar and sun photometer measurements; a review of such studies can be found in a recent publication (Binietoglou et al., 2015). However, in these retrievals the mean radii and refractive indices of particles in the fine and the coarse mode are assumed to be height independent, and only particle volume in each of the modes is permitted to vary. Such assumptions may become invalid when aerosol layers of different origins occur.

The alternative approach to evaluating the vertical distribution of dust properties is to estimate the particle properties from lidar measurements only. Raman (or HSRL) multiwavelength lidars based on a tripled Nd:YAG laser are able to provide three particle backscattering and two extinction coefficients (called the $3 \beta+2 \alpha$ data set). Different techniques have been considered to invert these measurements into parti- cle microphysics (Ansmann and Müller, 2005), but the main issue is a small number of input measurements (typically five), compared to the numerous parameters needed for describing the aerosol microphysical properties. This implies that the inverse problem is underdetermined and that numerous solutions may reproduce the input measurements with similar accuracy. This family of solutions can be localized by applying constraints to the "search space", i.e., limiting the range of the particle radii and refractive indices considered. The additional assumption usually made is that the refractive index is spectrally independent and identical over the whole size range (Müller et al., 1999; Veselovskii et al., 2002). Such an approach has proved to be efficient for aerosol particle size distributions (PSDs) with a predominant fine mode as, for example, in the case of biomass burning aerosols (Müller et al., 2005; Veselovskii et al., 2015a). However, in the case of dust, the inversion of lidar measurements becomes more challenging since the dust PSD contains a strong coarse mode with particle radii extending up to $\sim 15 \mu \mathrm{m}$, and the estimation of properties for such big particles is less accurate when measurements are only performed in the wavelength range of $355-1064 \mathrm{~nm}$. Moreover, dust particles are of irregular shape and Mie theory is thus not applicable for computations of their scattering properties. Also, the imaginary part of the refractive index (RI) of dust is spectrally dependent, with a strong enhancement of the absorption in the UV region (Patterson et al., 1977). And finally, particles in the fine and coarse mode may have different origin, so the size dependence of the refractive index should also be considered. The complexity of the problem outlined above demands the use of assumptions and simplifications in the retrieval algorithms.

A widely used model for treating irregularly shaped particles is the one used in the operational AERONET algorithm that mimics dust scattering properties with an assembly of randomly oriented spheroids (Mishchenko et al., 1997; Dubovik et al., 2006). For typical dust PSDs the AERONET model provides lidar and depolarization ratios which agrees reasonably well with observed values (Wiegner et al., 2009). The first attempts to invert lidar dust measurements into particle microphysics using the spheroids model were recently made (Veselovskii et al., 2010; Di Girolamo et al., 2012; Papayannis et al., 2012) but were applied to lofted layers of aged dust over Europe. The only test of the spheroidal model relevant to pure dust was performed by using the data acquired during the SAMUM-1 and SAMUM-2 campaigns (Müller et al., 2013). Results indicate that the effective radii derived from lidar measurements are in reasonable agreement with the values provided by AERONET and airplane sampling, while differences are significant for the refractive index.

The application of spheroids to the analysis of lidar dust observations is an important step forward when compared to the spherical particle approximation of Mie theory. Still, we should keep in mind that the spheroid model was not specifically designed for lidar applications where scattering in the 
backward direction is considered. For instance, as previously discussed (Gasteiger et al., 2011; Müller et al., 2013) the spheroidal model has difficulty in reproducing depolarization ratios $(\delta)$ greater than $30 \%$, values that are representative for pure dust. When using the spheroidal model, such high depolarization ratios can only be obtained when the real $\left(m_{\mathrm{R}}\right)$ and imaginary $\left(m_{\mathrm{I}}\right)$ parts of the refractive index are less than 1.5 and 0.005 , respectively (Dubovik et al., 2006), even though coincident in situ measurements of dust report higher values (Kandler et al., 2011). To investigate these issues, more measurements near the dust origin source and more tests of suitable inversion schemes are needed.

West Africa and the adjacent oceanic regions are very important locations for studying dust properties and their influence on weather and climate. The SHADOW campaign is performing a multiscale and multilaboratory study of aerosol properties and dynamics using a set of in situ and remote sensing instrumentation (multiwavelength Raman lidar, wind lidar, nephelometer, aethalometer, sun/lunar photometer, airborne sun photometer, optical particle counter) in the framework of the CaPPA (Chemical and Physical Properties of the Atmosphere) project (http://www.labex-cappa.fr/). The objective of the experiment is to report the optical, chemical, and physical properties of the aerosols as well as the source apportionment in a location where aerosol loading can be very large and aerosol type depends on the season. Two enhanced observing periods of 7 weeks are considered: MarchApril 2015 when dust due to the Harmattan, which is a dry trade wind that transports dust-laden air from the Sahara to west Africa (Schwanghart and Schütt, 2008), is dominant, and December 2015-January 2016 when dust and carbonaceous aerosols resulting from fire activities are in variable proportion and transported at different altitudes. Other types of aerosols can also be present, such as sulfates from nearby urban areas or maritime aerosols depending on the air mass flow. The mixed state of these various chemical components results in different radiative properties of the aerosols.

We hereinafter focus our study on multiwavelength MieRaman lidar measurements performed during the first phase of the SHADOW campaign for the period 8 March-24 April 2015. During this period approximately 40 day- and nighttime measurement sessions were performed and numerous strong dust episodes were observed. Those lidar observations are used for the analysis of the vertical distribution of the dust-intensive and microphysical properties. In Sect. 2 we describe the lidar equipment and the meteorological characteristics of the observation site. Section 3 presents day-to-day variation of dust properties and examples of vertical distribution of dust-intensive parameters. The results of inversion of lidar measurements into particle microphysics are given in Sect. 4.

\section{Instrumentation and meteorology of the observation site}

\subsection{Instrumentation}

The site is located at the Institute for Research and Development (IRD) in Mbour, Senegal $\left(14^{\circ} \mathrm{N}, 17^{\circ} \mathrm{W}\right)$. Aerosol observations with the AERONET sun photometer (Holben et al., 1998) and micropulse lidar have been performed since 1996 and 2005, respectively. Moreover, for the period of the SHADOW experiment, two additional lidar systems were installed: a Doppler wind lidar and a multiwavelength MieRaman lidar.

\subsubsection{Doppler lidar}

The wind field within the lower troposphere $(<5 \mathrm{~km})$ was measured by an eye-safe scanning wind lidar (Windcube WLS 100) manufactured by the LEOSPHERE company (www.leosphere.com). This pulsed Doppler lidar operates at $1543 \mathrm{~nm}$ with a repetition rate of $10 \mathrm{kHz}$ and uses a heterodyne technique to measure the Doppler shift of laser radiation backscattered by aerosols. Simultaneous measurements of radial wind speed and aerosol backscatter provides information on both aerosol layer stratification and the dynamics of the lower troposphere (Thobois and Soderholm, 2015). More technical details are given by (Kumer et al., 2014; Ruchith and Ernest Raj, 2015).

During this experiment, continuous monitoring of the wind field in the range from $100 \mathrm{~m}$ to $5 \mathrm{~km}$ with $50 \mathrm{~m}$ range resolution was performed. The total scanning cycle included two $180^{\circ}$ scans in the vertical plane along the east/west and south/north axes with a $1^{\circ}$ resolution, a $360^{\circ}$ azimuthal scan with $2^{\circ}$ resolution at a $5^{\circ}$ elevation angle, and line of sight (LOS) profiles at $75^{\circ}$ elevation in the four cardinal directions. The duration of the total cycle was approximately $10 \mathrm{~min}$. The combination of LOS sequences is used in order to determine the three components of the wind vector vertical profile relying on the Doppler Beam Swinging (DBS) technique (Browning and Wexler, 1968).

\subsubsection{Multiwavelength Mie-Raman lidar}

The LILAS multiwavelength Mie-Raman lidar is based on a tripled Nd:YAG Spectra Physics INDI laser with a $20 \mathrm{~Hz}$ repetition rate, and pulse energy of $90 / 100 / 100 \mathrm{~mJ}$ at $355 / 532 / 1064 \mathrm{~nm}$. The backscattered light is collected by a $40 \mathrm{~cm}$ aperture Newtonian telescope, which is inclined at an angle of $47^{\circ}$ to the horizon. Measurements were performed from inside the IRD building through a window and $47^{\circ}$ to horizon was the maximal angle possible. The outputs of the detectors (R1924, R9880 PMTs for the 355-532 nm spectral range and APD for $1064 \mathrm{~nm}$ ) are recorded at $7.5 \mathrm{~m}$ range resolution using Licel transient recorders that incorporate both analog and photon-counting electronics. The full geometrical overlap of the laser beam and the telescope FOV is 
achieved at $800-1400 \mathrm{~m}$ range depending on FOV used. The system is designed for simultaneous detection of elastic and Raman backscatter signals and thus provides three particle backscattering and two extinction coefficients along with depolarization ratio at $532 \mathrm{~nm}$ (called the $3 \beta+2 \alpha+1 \delta$ set). For the calibration of depolarization measurements, the so-called $\pm 45^{\circ}$ method, (Freudenthaler et al., 2009) was used. The relative uncertainty of depolarization measurements due to calibration is estimated as $\pm 15 \%$. Acquiring Raman backscatter at $408 \mathrm{~nm}$ permits profiling the water vapor mixing ratio (WVMR) (Whiteman et al., 1992). For calibration of the WVMR, radiosonde launches from the Dakar airport, located $\sim 70 \mathrm{~km}$ from Mbour, were used. The large separation between the lidar and radiosonde locations prevented an accurate calibration of the WVMR so the WVMR data were used mainly to monitor the relative change of the water vapor content. To improve the system capability for measurements of particle extinction coefficients at $532 \mathrm{~nm}$, rotational Raman (RR) scattering was used instead of vibrational nitrogen Raman scattering at $608 \mathrm{~nm}$ (Veselovskii et al., 2015b). For each profile, 4000 laser pulses were accumulated so the temporal resolution of the measurements was approximately $3 \mathrm{~min}$. The backscattering coefficients and depolarization ratio were calculated with a range resolution of $7.5 \mathrm{~m}$ (corresponding height resolution of $5.5 \mathrm{~m}$ ). Resolution of extinction coefficient measurements varied with height from $50 \mathrm{~m}$ (at $1000 \mathrm{~m}$ ) to $125 \mathrm{~m}$ (at $7000 \mathrm{~m})$.

\subsection{Meteorological characteristics of the observation site}

During the experimental period, complex lower tropospheric $(<3000 \mathrm{~m})$ stratification was frequently observed over the site. As we will show, this was likely due to the different origins of air masses, including tropical circulation arriving from maritime (moist) and continental trade winds (dry). Moreover, a transitional form of these two main trade winds were observed and described as continentalized maritime trade (CMT) winds. Thus, during the SHADOW campaign, the wind fields over the site were characterized by maritime trades (NW), continentalized maritime trades ( $\mathrm{N}$ to NNE), sea breezes (WSW to WNW), and continental trades (Harmattan); the latter indicates the presence of air mass advection coming from the northeastern/eastern drylands. One particularity of this site was the presence of recurrent lowlevel jets (NNW to ENE) which occurred during approximately $69 \%$ of the campaign period and were located below $1000 \mathrm{~m}$ in elevation. The transport paths of different stratified air masses were studied by using back-trajectories from the NOAA HYSPLIT model (Stein et al., 2015).

Figures 1-4 were derived from joint use of wind and Raman lidar measurements on the night of 15-16 April 2015 and illustrate the aerosol stratification that frequently characterized the observation site. For the period from 23:00 to 07:00 UTC on 15-16 April 2015 night, the time-height sec-

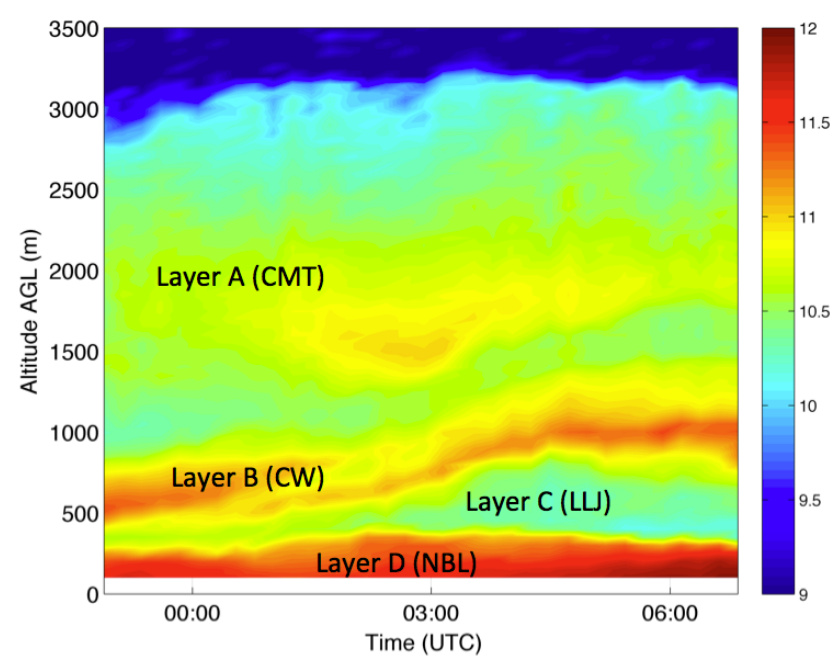

Figure 1. Time-height section of the logarithmic range corrected lidar signal (in arbitrary units) deduced from the Doppler lidar measurements during the night of 15-16 April 2015 at Mbour. The stratification is represented by four layers: (A) continentalized maritime trade (CMT); (B) layer advected mainly by a continental wind (CW); (C) low-level jet (LLJ); and (D) nocturnal boundary layer (NBL).

tions of the logarithmic range corrected signal (LRCS) is shown in Fig. 1, while Fig. 2 shows the horizontal wind speed (color scale) and direction (arrow) deduced from wind lidar and the sonic anemometer wind measurements near the ground. Back trajectories of the air masses ending in Mbour on 16 April 2015 at 2500 m (02:00 and 06:00 UTC), at $900 \mathrm{~m}$ (00:00 UTC), and at $700 \mathrm{~m}$ (06:00 UTC) are reported in Fig. 3. These figures reveal complex stratification and dynamics of the lower troposphere on 15-16 April: we can distinguish four layers (A-D) from $100 \mathrm{~m}$ to a height of approximately $3000 \mathrm{~m}$. In parallel, the wind field highlights that the appearance of multilayered wind structure mainly consisted of a northerly wind (downward arrow) prevailing near the ground, which changed to an easterly wind (leftward arrow) with height (Fig. 2).

- Layer A, located between 1000 and $3000 \mathrm{~m}$ (at 00:00 UTC), is associated with a small northerly wind speed $\left(<5 \mathrm{~m} \mathrm{~s}^{-1}\right)$ in the lower part of the layer, and a slightly larger easterly wind speed $\left(>5 \mathrm{~m} \mathrm{~s}^{-1}\right)$ above $2000 \mathrm{~m}$. Layer A can be considered to be a CMT wind which is one of oceanic origin that has been progressively altered by continental trade (CT), as follows from the back trajectories shown in Fig. 3. Therefore, this layer is characterized by a mixture of maritime and continental air.

- Layer B, located between 400 and $800 \mathrm{~m}$, rises progressively at the beginning of the study period up to 700$1000 \mathrm{~m}$ by the end of the data set. This layer is characterized by northeasterly winds and high aerosol loading. 


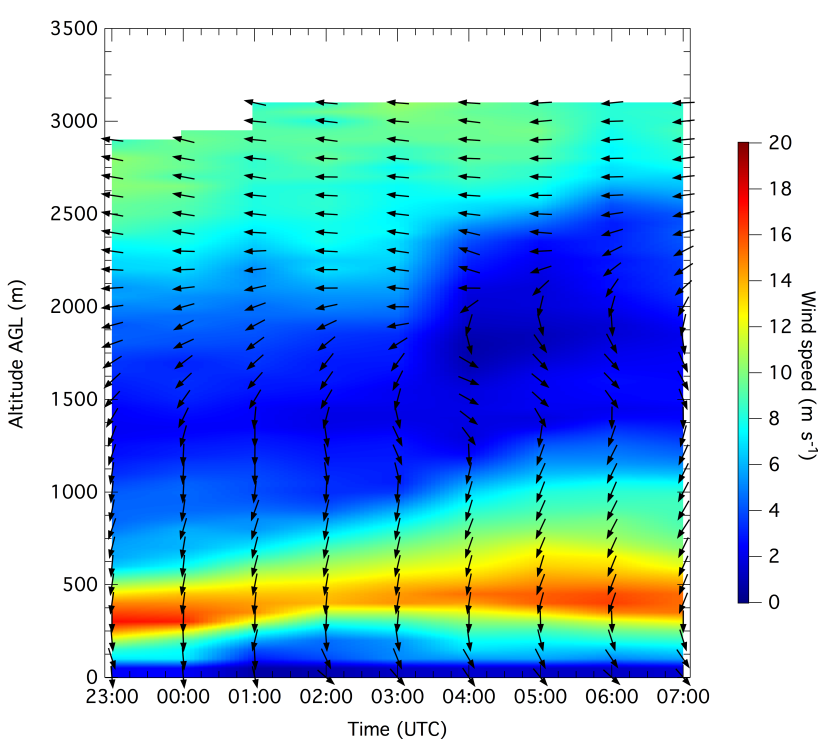

Figure 2. Time-height section of horizontal wind direction (arrows) and wind speed (color map) deduced from Doppler lidar during 1516 April. Leftward and downward arrows represent, respectively, easterly wind and northerly wind.

According to the back trajectories shown in Fig. 3, this air mass was transported from a continental area (Mali) and was mainly advected by a southeasterly continental wind $(\mathrm{CW})$.

- Layer C is a nocturnal low-level jet (LLJ). The jet core height is between 250 and $400 \mathrm{~m}$ with a maximum jet speed exceeding $15 \mathrm{~m} \mathrm{~s}^{-1}$. The LLJ was observed throughout the night with a thickness that progressively increased with time, perhaps being the causative mechanism for the corresponding increase in height of layer B (Fig. 1). The LRCS values within layer $\mathrm{C}$ decrease progressively up to the end of the observation period, perhaps due to dilution of the aerosol loading.

- Finally, layer D corresponds to the nocturnal boundary layer (NBL) characterized by high LRCS values and by small northerly or northwesterly wind speed $\left(<5 \mathrm{~m} \mathrm{~s}^{-1}\right)$. The NBL top can be deduced from the LRCS profile discontinuity (Seibert et al., 2000) and is estimated as approximately $200-300 \mathrm{~m}$ during the night.

Figure 4 shows the particle extinction coefficient at $532 \mathrm{~nm}$ (Fig. 4a), water vapor mixing ratio (Fig. 4b), lidar ratio (Fig. 4c), and depolarization ratio (Fig. 4d) both at $532 \mathrm{~nm}$ for the same time-height section as in Figs. 1 and 2. The water vapor can be used as a convenient tracer to separate dry continental air masses from oceanic air masses that are characterized by higher vapor content. Due to the geometrical overlap factor, the LILAS minimum height of the measurements shown in Fig. 4 is $800 \mathrm{~m}$. Still, layer B (CW) is well observed starting at 03:00 UTC (Fig. 4a) due to the increase

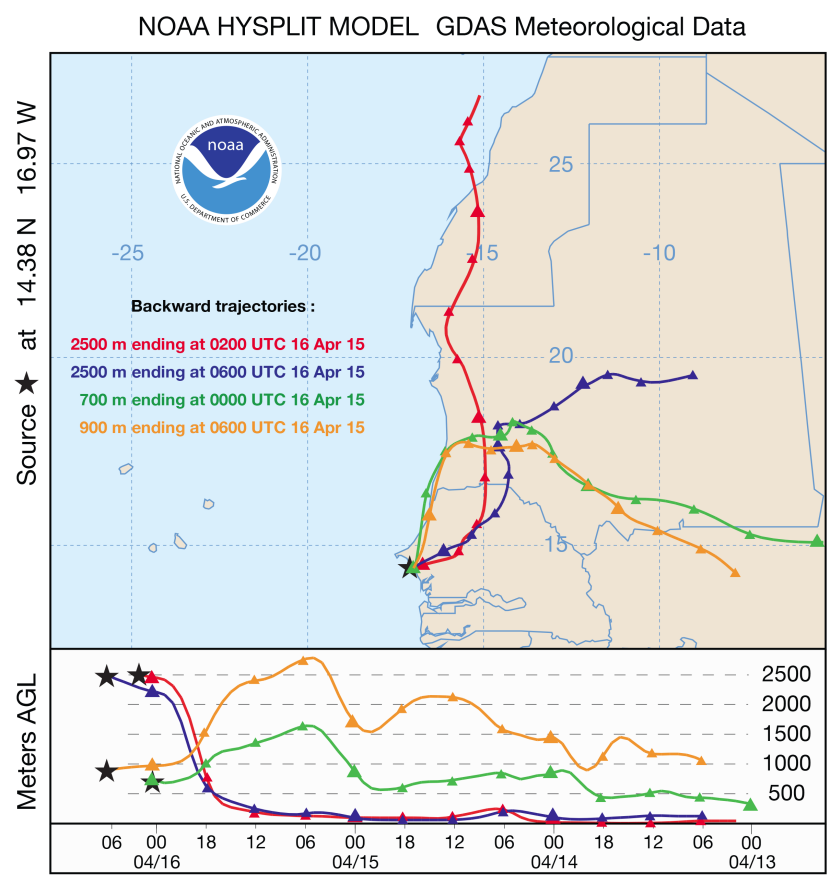

Figure 3. Back trajectories of the air masses ending in Mbour on 16 April 2015 at $2500 \mathrm{~m}$ (02:00 and 06:00 UTC), $700 \mathrm{~m}$ (00:00 UTC), and $900 \mathrm{~m}$ (06:00 UTC). The first two back trajectories correspond layer A from Fig. 1, while the last two back trajectories correspond layer B from the same figure.

of the layer height. The particle extinction coefficient $\alpha_{532}$ in layer A increases after 03:00 UTC while the mixing ratio is decreasing (Fig. 4b). This may indicate that continental air mass advected by $\mathrm{CT}$ has become dominant. The lidar ratio $\mathrm{LR}_{532}$ of the particles associated with $\mathrm{CT}$ is about $55 \mathrm{sr}$ while for CMT as observed during the first part of the observation period, it is lower (about $45 \mathrm{sr}$ ). The depolarization ratio $\delta_{532}$ is about $30 \%$ in layer $\mathrm{A}$ and shows a small enhancement up to $35 \%$ for layer B. We should mention also, that for air masses which we consider as "continentalized maritime" the particle depolarization ratio is in excess of $25 \%$, implying a significant amount of dust even in this layer.

To quantify vertical variations of water vapor mixing ratio and extinction coefficient $\alpha_{532}$, Fig. 5 shows the corresponding vertical profiles averaged over the period 05:0006:00 UTC. The WVMR in layer B containing dry continental air mass (at $1000 \mathrm{~m}$ ) is approximately one-half of the values outside of the layer (at $1500 \mathrm{~m}$ ). In layer A at $2800 \mathrm{~m}$ WVMR is approximately 1.5 times higher compared to layer $\mathrm{B}$, because layer A consists of a mixture of continental and oceanic air mass. These results demonstrate that water vapor, being a generally conserved quantity, is a helpful tracer for aiding the identification of air mass origin. 

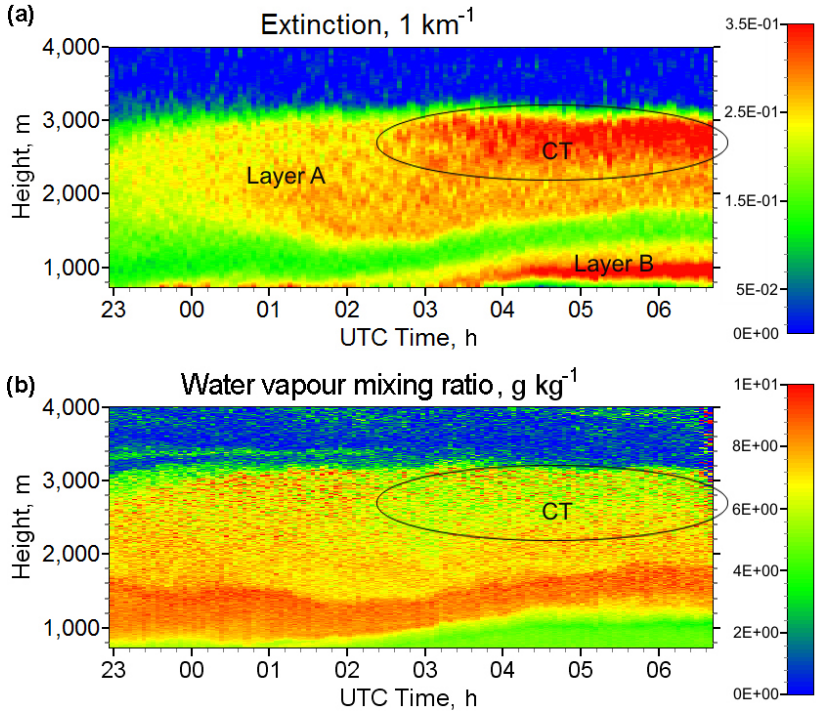

(c)
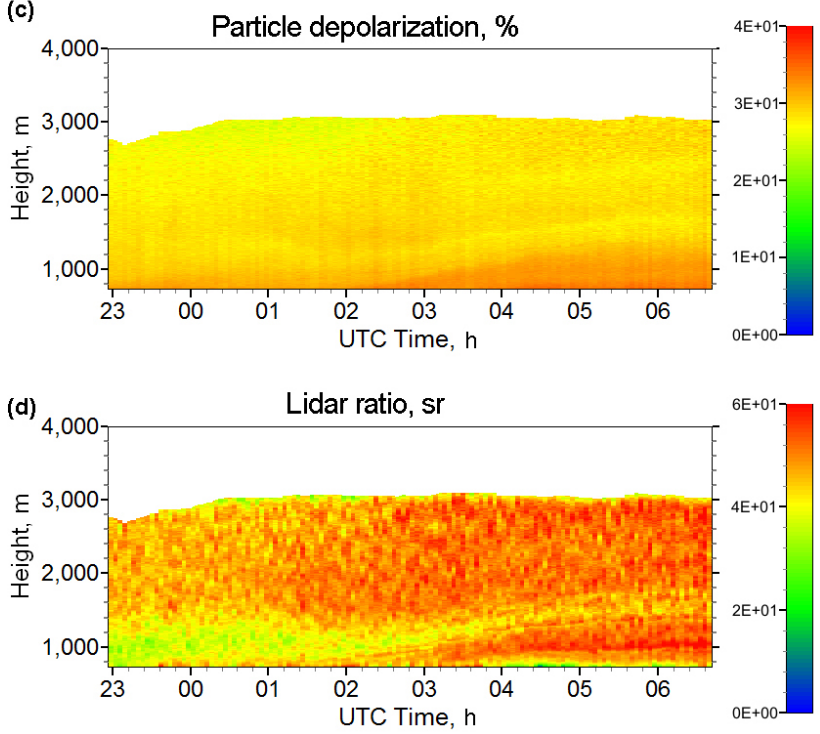

Figure 4. Height-temporal distribution of particle characteristics: (a) extinction coefficient $\alpha_{532}$, (b) water vapor mixing ratio, (c) particle depolarization, and (d) lidar ratio $\mathrm{LR}_{532}$ measured during the night of 15-16 April 2015.

\section{Dust particle properties derived from Raman lidar observations}

\subsection{Day-to-day variation of particle-intensive parameters}

One of the goals of the SHADOW campaign was to study the dust-particle-intensive parameters, such as extinction and backscattering Ångström exponents together with lidar and depolarization ratios. During March-April 2015, about 40 measurement sessions, including both day- and nighttime periods, were performed. In the analysis presented below, only nighttime measurements are considered, and for every

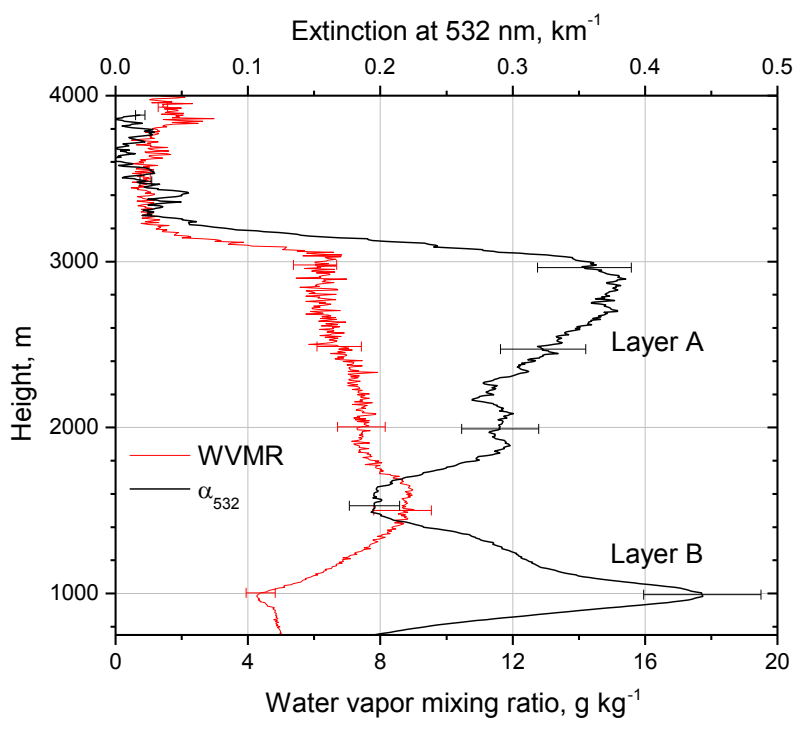

Figure 5. Vertical profiles of particle extinction coefficients at $532 \mathrm{~nm}$ and water vapor mixing ratio on 16 April 2015. Results are averaged over the 05:00-06:00 UTC temporal interval.

session all lidar signals measured during the night are temporally averaged. Moreover, for an evaluation of day-to-day variations of the particle parameters we use only extinction and backscattering coefficients averaged within the 1500 $2000 \mathrm{~m}$ height layer, where a high dust concentration is frequently observed. For such extensive averaging the uncertainties of derived parameters are mainly due to the systematical errors. Thus, we estimate the uncertainty of extinction coefficient and lidar ratio calculation to be below 10 and $15 \%$, respectively, for both wavelengths. Uncertainties of extinction and backscattering Ångström exponents' derivation are estimated to be below \pm 0.2 . It should be mentioned that only observations with particle depolarization great than $20 \%$ were selected to indicate a major dust contribution. The days with lower depolarization were characterized also by low particle extinction so we were not able to calculate intensive parameters with sufficient accuracy.

To give an overview of the variation in aerosol loading, the aerosol optical thickness (AOT) at $440 \mathrm{~nm}$ together with the extinction Ångström exponent (EAE) $A_{380 / 500}^{\alpha}$ measured with a Cimel sun photometer is reported in Fig. 6 for the 10 March-23 April 2015 period. The AOT was relatively low (mainly below 0.4 ) for 17-28 March, but increased after 28 March reaching values up to 2.0. The high AOTs are associated with low values of the extinction Ångström exponent indicating numerous dust episodes (days with increased dust content). Figure 7 shows the particle extinction coefficient $\alpha_{532}$ together with EAE and BAE $A_{355 / 532}^{\alpha}, A_{355 / 532}^{\beta}$ derived from the lidar measurements for the same time period. During 28 March-15 April several strong dust episodes occurred as indicated by averaged overnight values of extinction coefficients as high as $0.5 \mathrm{~km}^{-1}$. For $85 \%$ of the considered 


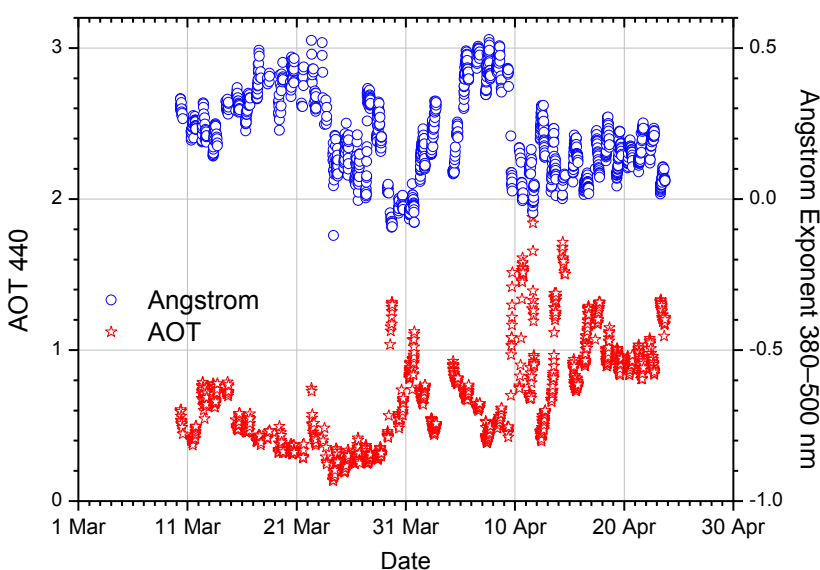

Figure 6. Aerosol optical thickness (AOT) at $440 \mathrm{~nm}$ and the extinction Ångström exponent at 380-550 nm wavelengths provided by AERONET in Mbour for the period of March-April 2015.
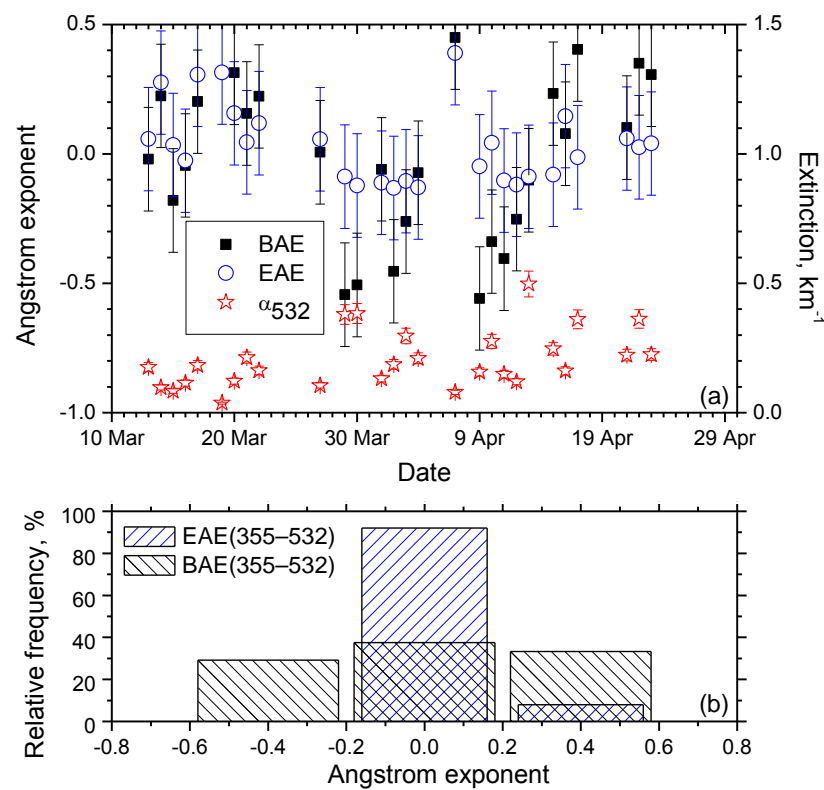

Figure 7. (a) Particle extinction coefficient at $532 \mathrm{~nm}$ together with backscattering and extinction Ångström exponents at 355/532 nm, derived from lidar measurements within the 1500-2000 m layer for the period of March-April 2015. (b) Frequency distributions of $\mathrm{BAE}$ and EAE.

cases, EAE is within the interval of $-0.2-0.2$ while values of BAE are distributed over the $-0.55-0.5$ range, because BAE is more sensitive to the change of complex refractive index (CRI).

The day-to-day variation of the lidar ratios at 355 and $532 \mathrm{~nm}$ together with particle depolarization ratio at $532 \mathrm{~nm}$ is shown in Fig. 8. The majority of the lidar ratios is contained within the range of $45-65 \mathrm{sr}$ (96 and $82 \%$ for 532 and $355 \mathrm{~nm}$, respectively) but for UV about $10 \%$ of the cases are between 65 and 75 sr. The mean values of lidar ra-
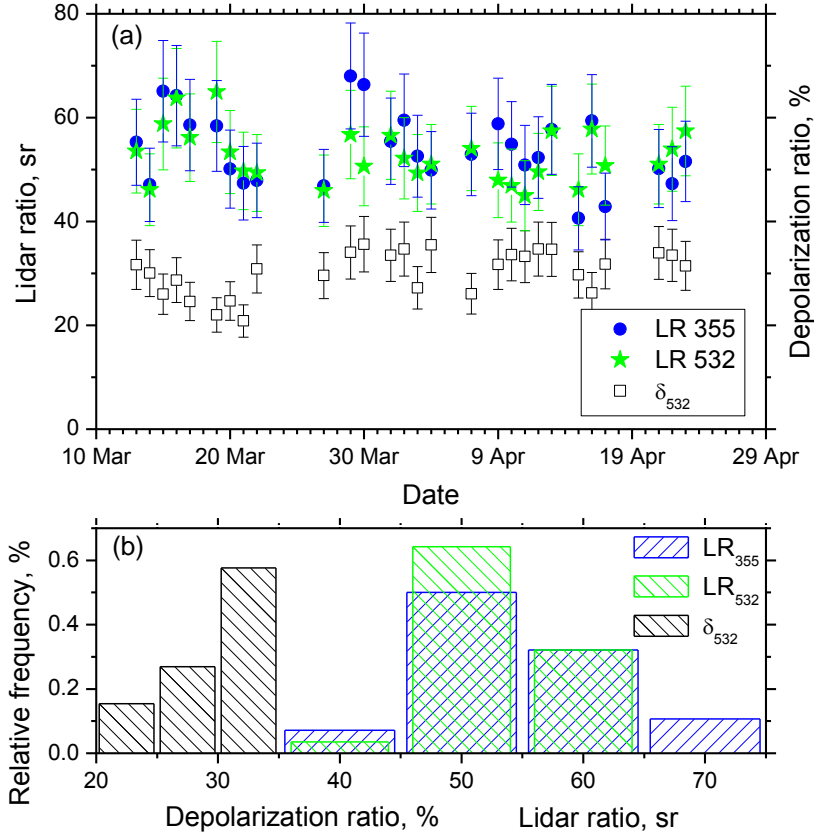

Figure 8. (a) Lidar ratios at 355 and $532 \mathrm{~nm}$ together with particle depolarization ratios at $532 \mathrm{~nm}$ derived from lidar measurements within the 1500-2000 m layer for the period of March-April 2015. (b) Frequency distribution of lidar and depolarization ratios.

tios for both wavelengths are similar: $\mathrm{LR}_{355}=54 \pm 8 \mathrm{sr}$ and $\mathrm{LR}_{532}=53 \pm 8 \mathrm{sr}$. The mean value of the particle depolarization ratio is $30 \pm 4.5 \%$; however, during the dust events the depolarization ratio could increase up to $35 \pm 5 \%$.

\subsection{Vertical distribution of particle-intensive properties}

The vertical distribution of particle-intensive properties is strongly influenced by the origin of the air masses which were coming either from ocean or continental regions during the SHADOW measurement period. In this section, we present the results for 3 days (13 March, 29 March, and 10 April 2015) characterized by different types of air masses.

\subsubsection{March}

As follows in Fig. 9, on 13 March at 21:00 UTC, the air masses at the three heights $(1500,2500$, and $3500 \mathrm{~m})$ were transported mainly over the ocean, but the back trajectory at $1500 \mathrm{~m}$ presents a "loop" over the continent, so the corresponding air masses may contain more dust compared to other heights. The relative humidity measured with meteorological sonde in Dakar was below $38 \%$ inside the 1000 $2600 \mathrm{~m}$ height range and it increased up to $75 \%$ above $3350 \mathrm{~m}$. Lidar measurements of water vapor mixing ratio are not available for this day. Figure 10 shows the vertical profiles of $3 \beta+2 \alpha$ measurements together with lidar ratios $\mathrm{LR}_{355}, \mathrm{LR}_{532}$, depolarization ratio $\delta_{532}$, and Ångström 


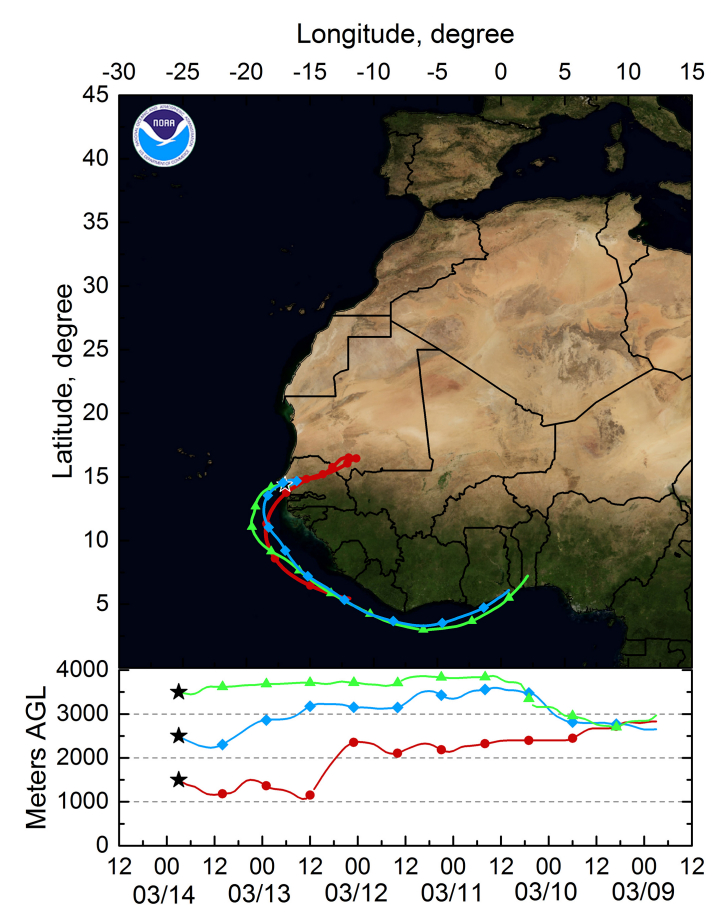

Figure 9. Five-day backward trajectories for the air mass in Mbour at altitudes of 1500,2500 , and $3500 \mathrm{~m}$ on 13 March 2015 at 21:00 UTC.

exponents $A_{355 / 532}^{\alpha}, A_{355 / 532}^{\beta}$ on 13 March 2015 averaged over the 20:30-21:30 UTC time period. The aerosol layer extended up to $3500 \mathrm{~m}$ but the extinction coefficient $\alpha$ was relatively small; at both 355 and $532 \mathrm{~nm}$, wavelengths $\alpha$ did not exceed $0.16 \mathrm{~km}^{-1}$. The particle depolarization ratio at $532 \mathrm{~nm}$ was approximately $31 \pm 4.5 \%$ inside the dust layer (up to $\sim 2750 \mathrm{~m}$ ) and decreased to less than $15 \%$ at $3250 \mathrm{~m}$. Likewise, the $A_{355 / 532}^{\alpha}$ and $A_{355 / 532}^{\beta}$ are close to zero up to $2750 \mathrm{~m}$, but start to increase, indicating the presence of smaller particles. The lidar ratios $\mathrm{LR}_{355}$ and $\mathrm{LR}_{532}$ are approximately $53 \pm 8 \mathrm{sr}$ inside the dust layer. Above $2750 \mathrm{~m}$, the values of LR are more noisy but do not seem to change.

\subsubsection{March}

The back trajectories from the night of 29-30 March associated with a strong dust case are shown in Fig. 11. The air masses at low altitude were transported over the continent and were strongly loaded with dust. The relative humidity was below $19 \%$ in the $600-1500 \mathrm{~m}$ height range. Figure 12 presents the vertical profiles of the same particle parameters as Fig. 10 but for 29 March. Lidar-measured water vapor mixing ratio, shown in the same figure, is below $2.5 \mathrm{~g} \mathrm{~kg}^{-1}$. The extinction coefficient $\alpha$ inside the dust layer (below $1500 \mathrm{~m}$ ) is greater than $0.6 \mathrm{~km}^{-1}$ for both wavelengths. The backscattering coefficient $\beta_{355} \mathrm{~nm}$ inside the dust layer is lower than $\beta_{532}$, which is consistent with the lidar ratio larger at $355 \mathrm{~nm}$ than that at $532 \mathrm{~nm}$ with values as large as $65 \mathrm{sr}$.
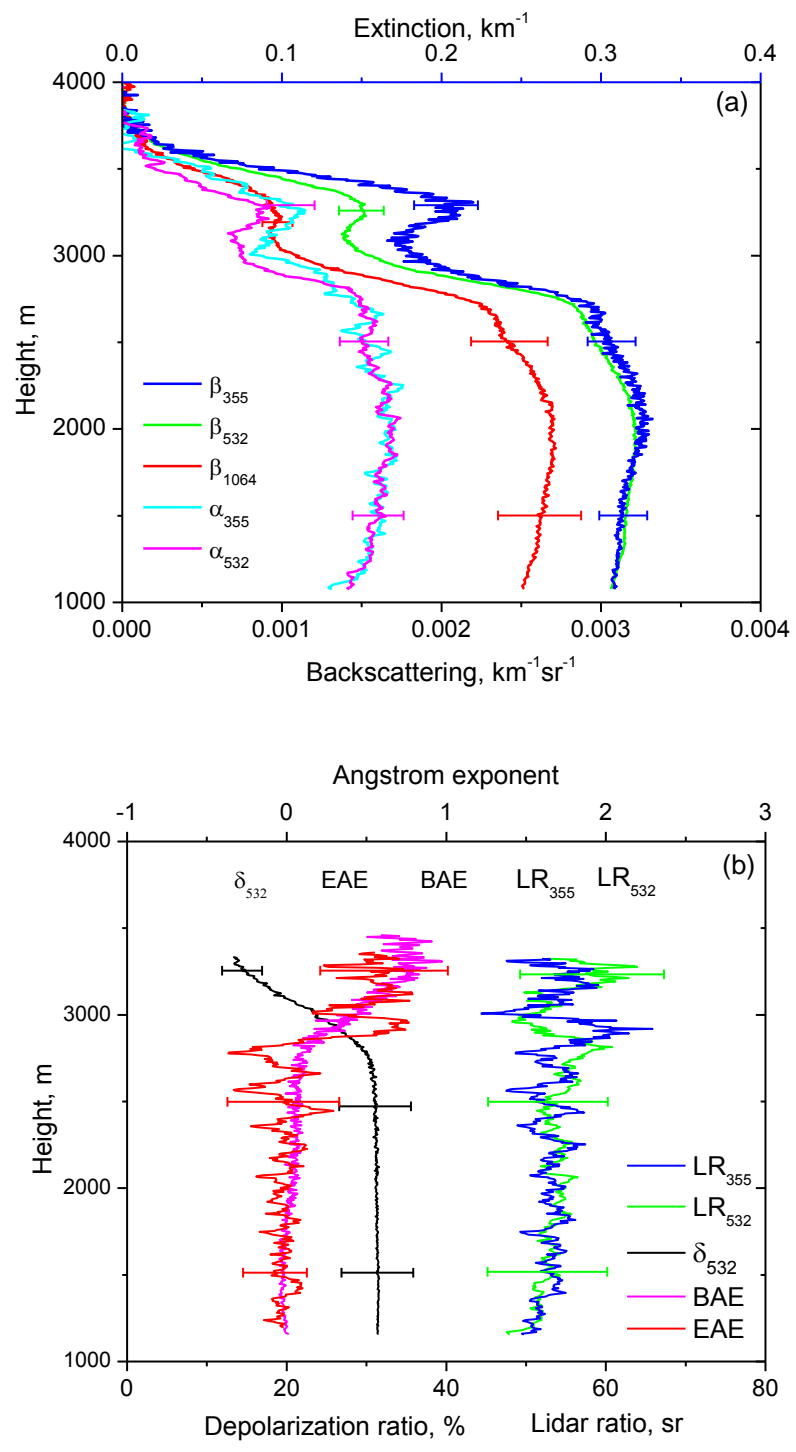

Figure 10. Vertical profiles of (a) backscattering and extinction coefficients and (b) lidar ratios, depolarization ratio, and backscattering and extinction Ångström exponents at 355/532 nm measured on 13 March 2015 for the period of 20:30-21:30 UTC.

The $A_{355 / 532}^{\beta}$ BAE is negative and gets near -0.8 , while EAE is still close to 0 as observed on 13 March (Fig. 10). The negative values of BAE can result from the spectral dependence of the imaginary part of the dust RI which is larger at 355 than at $532 \mathrm{~nm}$ (e.g., Patterson et al., 1977; Müller et al., 2009; Ansmann et al., 2011).

The ground-based measurements performed during the SAMUM campaign demonstrated that the imaginary part of the dust RI could vary from $m_{\mathrm{I}}=0.005$ at $532 \mathrm{~nm}$ to $m_{\mathrm{I}}=0.02$ at $355 \mathrm{~nm}$ (Ansmann, et al., 2011). Such a strong enhancement of $m_{\mathrm{I}}$ may lead to a decrease of the backscattering coefficient (Veselovskii et al., 2010). To estimate the impact of the $m_{\mathrm{I}}$ enhancement at $355 \mathrm{~nm}$ on the values of EAE 


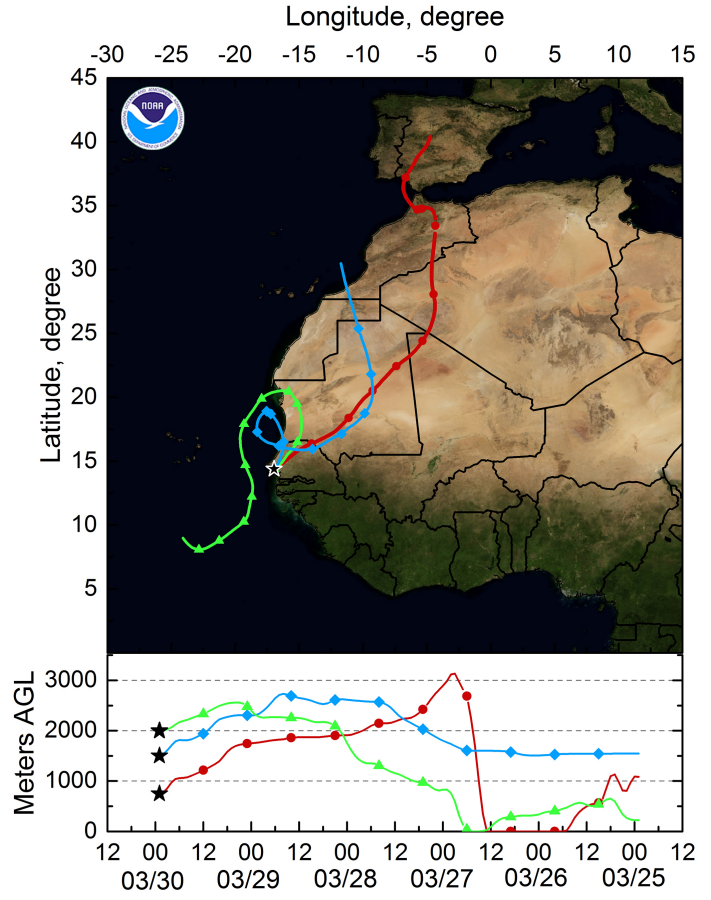

Figure 11. Five-day backward trajectories for the air mass in Mbour at altitudes of 750, 1500, and $2000 \mathrm{~m}$ on 29 March 2015 at 23:00 UTC.

and BAE at 355/532 nm wavelengths, numerical simulations were performed. Extinction and backscattering Ångström exponents were calculated using the model of randomly oriented spheroids as described in Veselovskii et al. (2010) for a bimodal particle size distribution:

$\frac{\mathrm{d} n(r)}{\mathrm{d} \ln (r)}=\sum_{i=\mathrm{f}, \mathrm{c}} \frac{N_{i}}{(2 \pi)^{\frac{1}{2}} \ln \sigma_{i}} \exp \left[-\frac{\left(\ln r-\ln r_{i}\right)^{2}}{2\left(\ln \sigma_{i}\right)^{2}}\right]$.

where $N_{\mathrm{f}, \mathrm{c}}$ is particle number density in the fine (f) and the coarse (c) mode. Each mode is represented by a log-normal distribution with modal radius $r_{\mathrm{f}, \mathrm{c}}$ and dispersion $\ln \sigma_{\mathrm{f}, \mathrm{c}}$. For the fine mode, values of $r_{\mathrm{f}}=0.1 \mu \mathrm{m}$ and $\ln \sigma_{\mathrm{f}}=0.4$ were used. For the coarse mode, $r_{\mathrm{c}}=1.0 \mu \mathrm{m}$ and three values $\ln \sigma_{\mathrm{c}}=0.4,0.5,0.6$ were considered. The three size distributions expressed in volume are reported in the insert of Fig. 13. The ratio $\mathrm{N}_{\mathrm{c}} / \mathrm{N}_{\mathrm{f}}$ in all cases was 0.01 , and the real part of CRI was 1.55 for all wavelengths. The imaginary part was fixed at 0.005 for $532 \mathrm{~nm}$ while it varied within the $0.005-$ 0.05 range at $355 \mathrm{~nm}$. Values of EAE and BAE as a function of $m_{\mathrm{I}}$ at $355 \mathrm{~nm}$ are given by Fig. 13. The EAE shows no significant sensitivity to changes in $m_{\mathrm{I}}$, but BAE decreases rapidly as a function of $m_{\mathrm{I}}$ at $355 \mathrm{~nm}$. The present sensitivity study is limited but illustrates the importance of accounting for the right spectral dependence of $m_{\mathrm{I}}(\lambda)$.
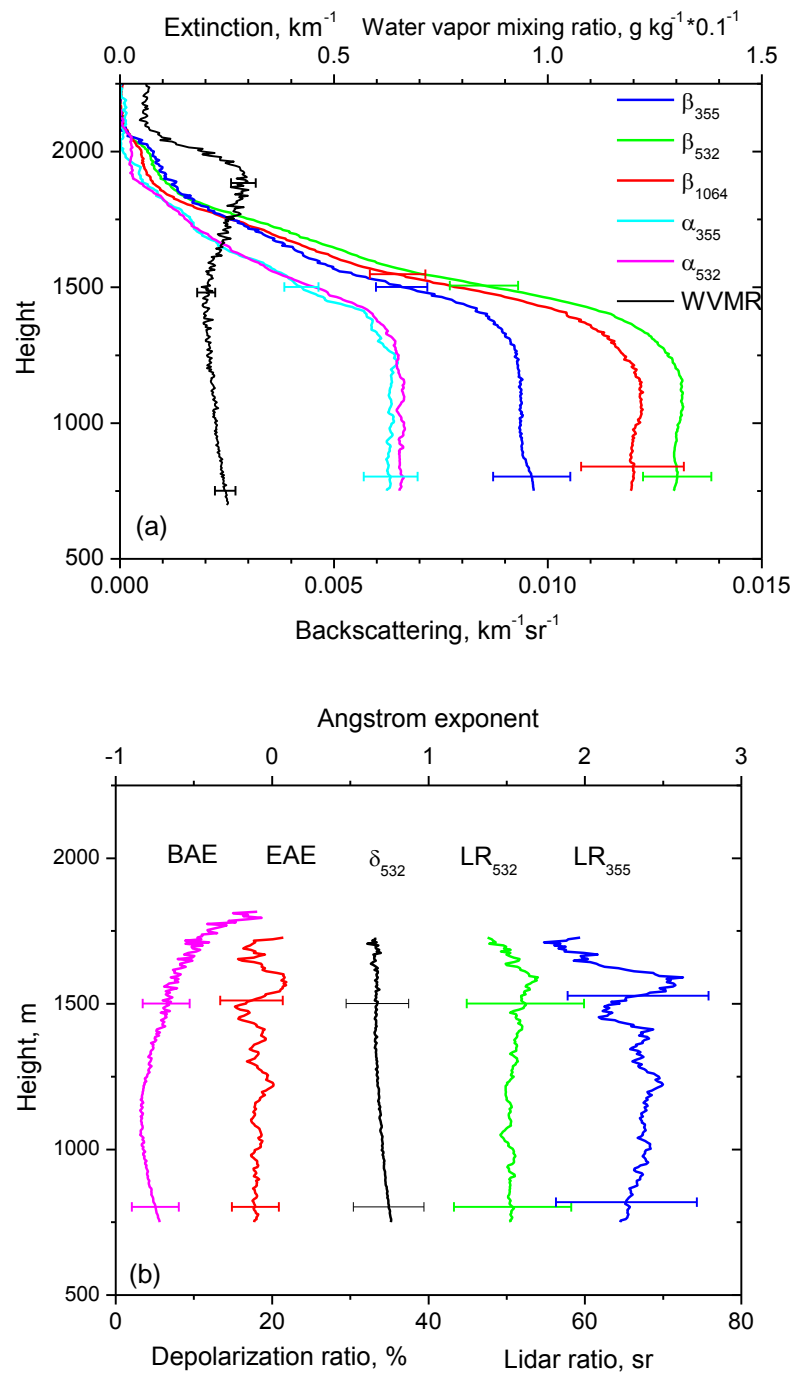

Figure 12. Vertical profiles of (a) backscattering and extinction coefficients and (b) lidar ratios, depolarization ratio, and backscattering and extinction Ångström exponents at 355/532 nm measured on 29 March 2015 for the period of 22:00-23:30 UTC.

\subsubsection{April}

On 10 April, the air masses were coming from continental regions and particle parameters showed large variation with height. We selected measurements during the period 00:00 02:00 UTC for which the backward trajectories at 01:00 UTC are shown in Fig. 14. The air masses at 2000 and $3000 \mathrm{~m}$ originate from the dust-laden continental region (barren or sparsely vegetated areas), while at $4500 \mathrm{~m}$ the air masses come from regions covered by grasslands and savannas. Figure 15 shows profiles of the $3 \beta+2 \alpha$ measurements together with particle-intensive parameters. The particle extinction coefficient increases with height reaching a maximum value of around $0.2 \mathrm{~km}^{-1}$ for both wavelengths at a height of approximately $3000 \mathrm{~m}$ and then decreases up to $5000 \mathrm{~m}$. The 


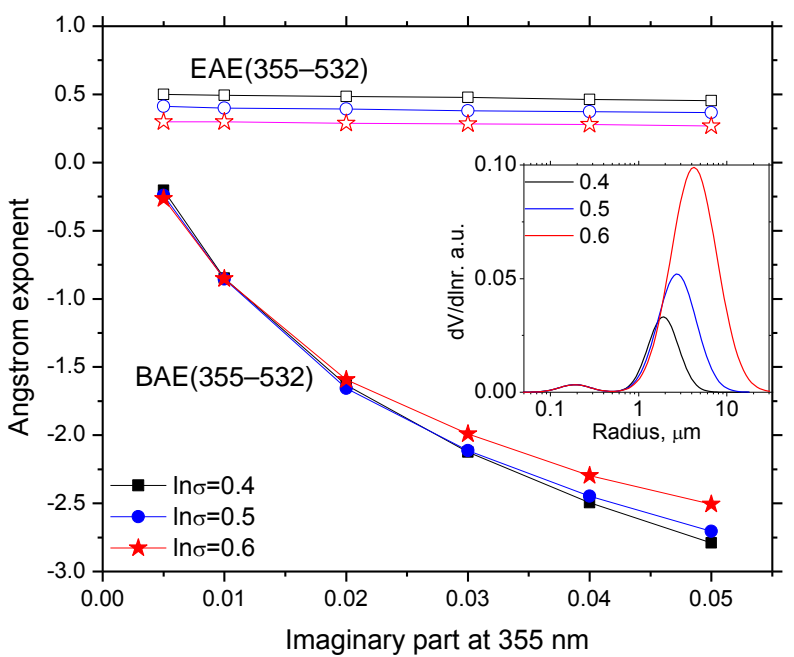

Figure 13. Extinction and backscattering Ångström exponent for $355 / 532 \mathrm{~nm}$ wavelengths as a function of the imaginary part of the refractive index at $355 \mathrm{~nm}$. The CRI at $532 \mathrm{~nm}$ was kept $m=$ $1.55-i .005$. Computations were performed using the model of randomly oriented spheroids. The insert shows three bimodal PSDs with $\ln \sigma=0.4,0.5,0.6$ used in computations.

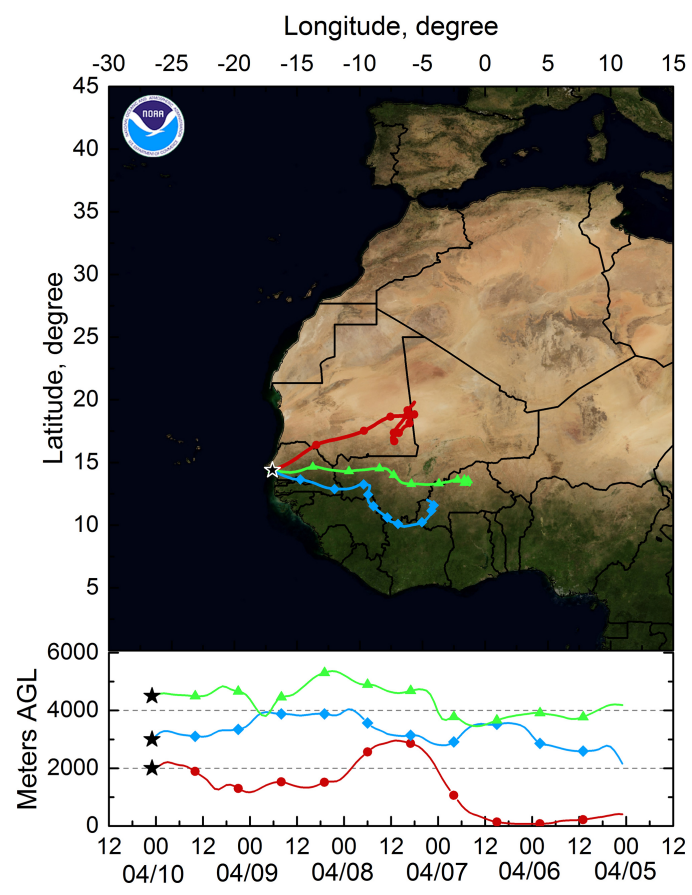

Figure 14. Five-day backward trajectories for the air mass in Mbour at altitudes of 2000, 3000, and $4500 \mathrm{~m}$ on 10 April 2015 at 01:00 UTC.

EAE is approximately zero up to $3000 \mathrm{~m}$ and then it increases to 1.0 at $4500 \mathrm{~m}$. The BAE below $3000 \mathrm{~m}$ is smaller with minimum value $A_{355 / 532}^{\beta} \approx-0.5$, but increases up to $4500 \mathrm{~m}$ where $\mathrm{EAE}$ and $\mathrm{BAE}$ are approximately equivalent. The de-
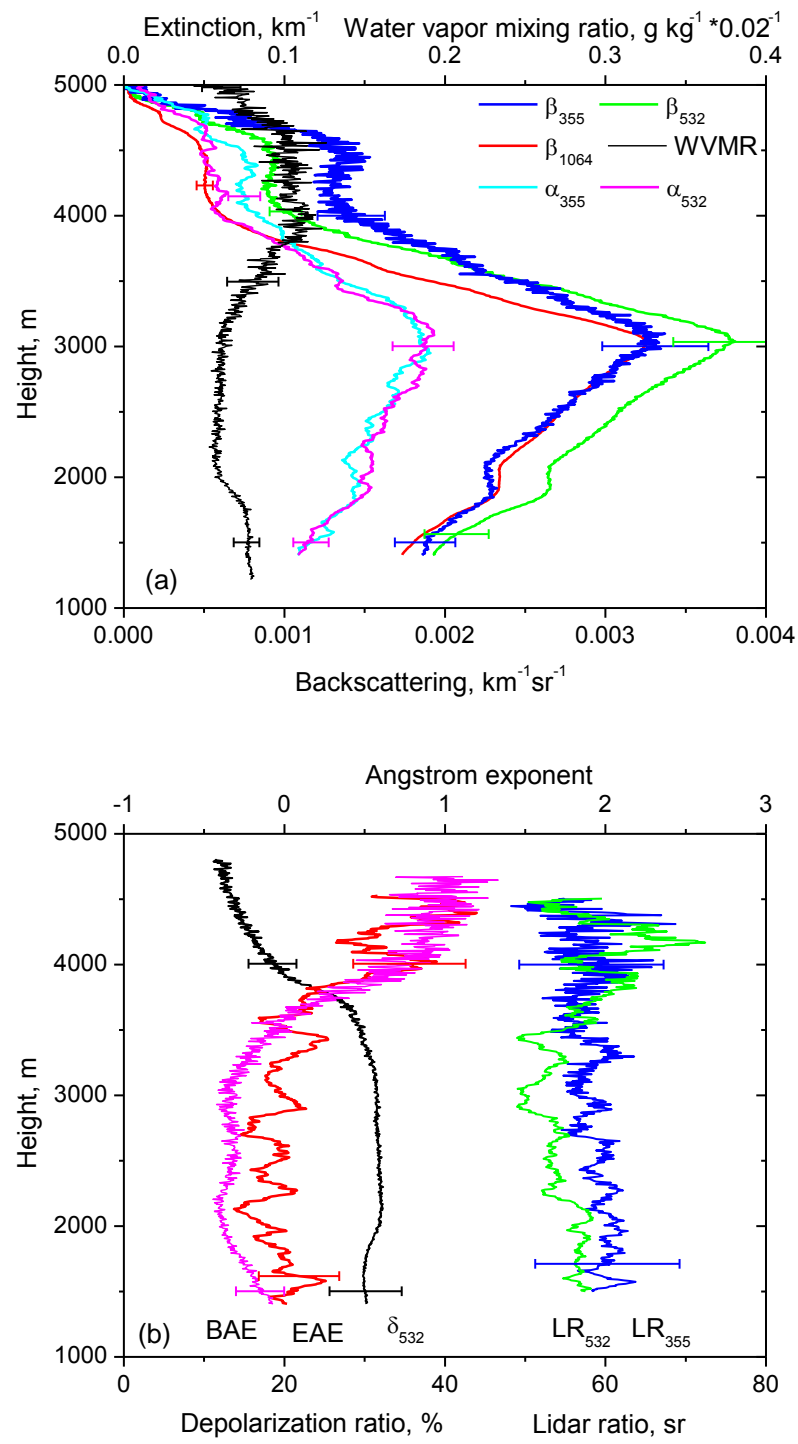

Figure 15. Vertical profiles of (a) backscattering and extinction coefficients and (b) depolarization ratio, backscattering and extinction Ångström exponents at 355/532 nm measured on 10 April 2015 for the period of 00:00-02:00 UTC.

polarization ratio is around $30 \%$ in the $2000-3500 \mathrm{~m}$ range, and decreases for higher altitudes. The lidar ratio at $355 \mathrm{~nm}$ inside $2000-3500 \mathrm{~m}$ layer exceeds that at $532 \mathrm{~nm}$ (averaged values are $60 \pm 9$ and $53 \pm 8 \mathrm{sr}$ correspondingly) and for higher altitudes the lidar ratios at both wavelengths are close. Thus, we can identify different aerosol layers with different properties: a mostly pure dust layer within the $2000-3500 \mathrm{~m}$ altitude range and mixed aerosols above it.

Figure 15 shows also the estimated profile of water vapor mixing ratio (WVMR) obtained from the lidar measurements. WVMR is less than $3 \mathrm{~g} \mathrm{~kg}^{-1}$ within the dust layer and increases above $3500 \mathrm{~m}$ reaching approximately $5.5 \mathrm{~g} \mathrm{~kg}^{-1}$ at $4000 \mathrm{~m}$. There are clearly two distinct layers. If the de- 
rived properties of aerosols within the lower layer are representative of dust, the air mass above $4000 \mathrm{~m}$ brings another particle type. Particles, characterized by lower depolarization ratio, are smaller since the EAE is increasing. Based on the analysis of the satellite data quick-looks (see for instance http://earthobservatory.nasa.gov/GlobalMaps/), the back trajectories reporting in Fig. 14 show that the air mass at $4500 \mathrm{~m}$ is coming from regions where fires were active during several days, which can result in emission of smoke particles transported over Mbour a few days later. The derived properties of aerosols within the 4000-5000 m layer are consistent with this hypothesis.

\section{Inversion of Raman lidar observations to the particle microphysics}

The lidar $3 \beta+2 \alpha$ and $3 \beta+2 \alpha+1 \delta$ observations analyzed in the previous sections can be inverted into microphysical properties using a regularization algorithm. As previously mentioned, in the case of irregularly shaped dust particles such inversion is more complicated compared to other aerosol types that may be well handled by spherical particle assumptions. In an earlier study, a model of randomly oriented spheroids for dust was used (Veselovskii et al., 2010). This model handles the dust particles as a mixture of spheres and spheroids, so an additional unknown parameter, spheroids' volume fraction (SVF), appears. The SVF in principle can be determined in the process of inversion of $3 \beta+2 \alpha+1 \delta$ measurements thanks to the use of the depolarization ratio as an input parameter. However, for the dust layers, in a first guess, we assume a value of SVF $=100 \%$ to decrease the number of retrieved parameters. The values of SVF $>98 \%$ provided by AERONET for the days considered here support this assumption. In the process of inversion, we used algorithm from Veselovskii et al. (2010) and the "search space" parameters similar to those described in Müller et al. (2013). The boundary of the inversion window has been set to the minimum and maximum particle radii of 0.075 and $15 \mu \mathrm{m}$, respectively. The real part of RI was allowed to vary in the range $1.35-1.65$, while the imaginary part varied in the range $0-0.02$. The refractive index was assumed to be spectrally independent. The effects of a possible spectral dependence of the imaginary part of RI will be considered at the end of this section.

Figure 16 shows the particle volume density retrieved from $3 \beta+2 \alpha$ measurements on 13 March, 29 March, and 10 April, which were discussed in Sect. 4.2. The profiles of particle volume are given together with corresponding extinction coefficients at $532 \mathrm{~nm}$. The volume-extinction ratio $V / \alpha_{532}$ for these days is also reported. Inside the dust layer this ratio varies within the range $(0.50-0.65) \times 10^{-6} \mathrm{~m}$, while outside the dust layer, the $V / \alpha_{532}$ ratio decreases. An overview of observed values of the volume-extinction ratio for dust, obtained from in situ AERONET and lidar measurements, is

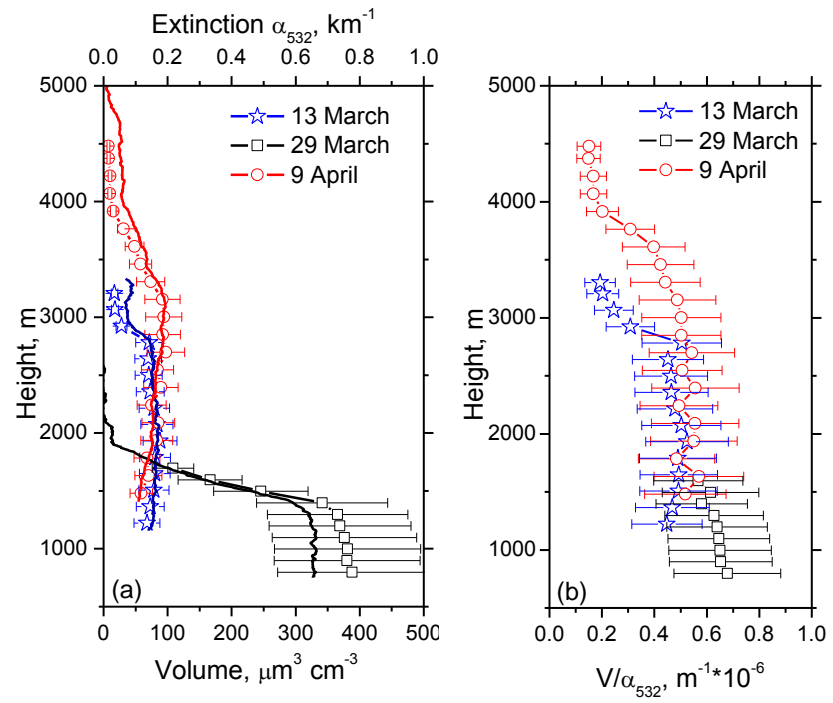

Figure 16. (a) Vertical profiles of the particle volume density $V$ (symbols) retrieved from $3 \beta+2 \alpha$ measurements on 13 March, 29 March, and 10 April. Solid lines indicate the profiles of extinction coefficient at $532 \mathrm{~nm}$. (b) The volume-extinction ratio $V / \alpha_{532}$ for the days considered.

presented in Ansmann et al. (2012) and provides $V / \alpha_{532}$ varying within the range $(0.60-1.29) \times 10^{-6} \mathrm{~m}$. Thus, our results are near the low boundary of these previously published results.

The profiles of the effective radius and the real part of RI are shown in Fig. 17. The inverted effective radius inside the dust layer is between 1.05 and $1.25 \mu \mathrm{m}(1.15 \pm 0.3 \mu \mathrm{m})$ and similar for the 3 days. The AERONET retrievals provided column-integrated values that are in the same range and agree within the uncertainty. On the early morning of $30 \mathrm{March}$, when the dust contribution to the AOT is prevailing, the effective radius $r_{\text {eff }}=1.36 \mu \mathrm{m}$ and it varies between 0.918 and 1.70 depending on the days and time. The lidar retrievals indicate that the real part of the CRI in the dust layer varied from $1.51 \pm 0.05$ to $1.57 \pm 0.05$, which is quite typical for desert dust (Patterson et al., 1977), while the AERONET retrievals yield values between approximately 1.46 and 1.58 depending on the days. Outside of the dust layer the retrieval of $m_{\mathrm{R}}$ is not reliable because the assumption of $\mathrm{SVF}=100 \%$ is not fulfilled and, as a result, the retrieved values of $m_{\mathrm{R}}$ are overestimated (Veselovskii et al., 2010).

The values of the imaginary part of the CRI retrieved from lidar measurements are approximately 0.007 inside the dust layer. However, the retrieved value is associated with average value over spectral range and characterized by high uncertainty (Müller et al., 2013). Still, this uncertainty does not significantly affect the retrieved values of volume and effective radius (Veselovskii et al., 2013).

The regularization approach also estimates the PSD, allowing us to conclude which of the modes (fine or coarse) is 


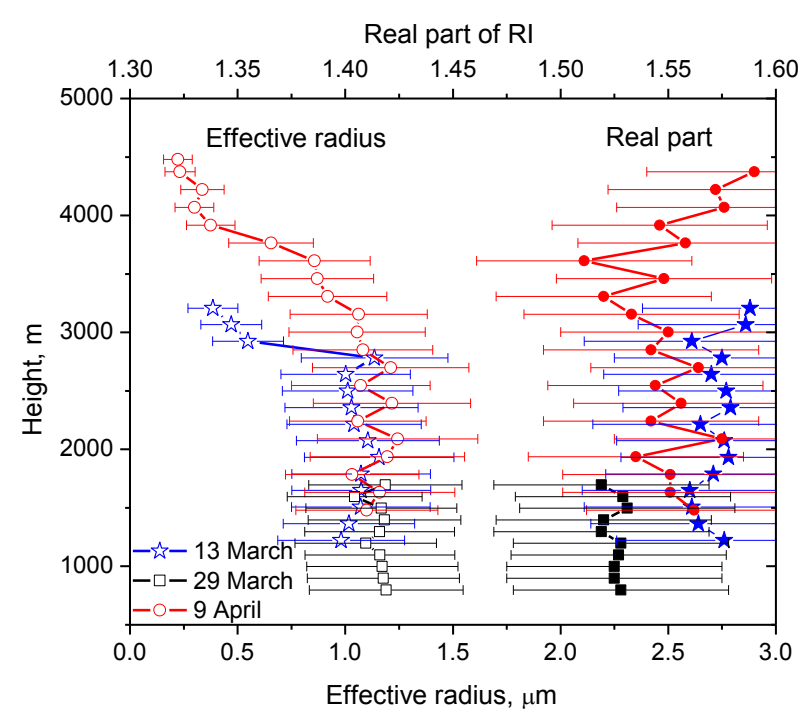

Figure 17. The profiles of the particle effective radius (open symbols) and the real part (solid symbols) of RI retrieved from $3 \beta+2 \alpha$ measurements on 13 March, 29 March, and 10 April.

predominant. Figure 18 shows the PSDs derived from lidar measurements on 10 April for four height layers of $150 \mathrm{~m}$ width centered at 1940, 3150, 4070, and $4370 \mathrm{~m}$ heights. For the layers with strong dust loadings $(1940,3150 \mathrm{~m})$ the coarse mode is dominant, at higher altitude outside the dust layer ( 4070 and $4370 \mathrm{~m}$ ), the fine mode (around $0.15 \mu \mathrm{m})$ prevails. For comparison, the column-integrated PSD obtained from AERONET level 1.5 data on 9 April at 18:00 UTC is also reported. The coarse mode looks shifted toward larger particles when compared to the lidar retrievals but the difference can be due to the spectral dependence of the imaginary part of $m_{\mathrm{I}}$, as it will be discussed further in this section.

Depolarization measurements provide additional information about particle properties that can be used in the inversion algorithm as long as the forward model can compute the particle depolarization ratio with sufficient accuracy. Hereafter, we compare the retrieved aerosol parameters using the $3 \beta+2 \alpha$ or $3 \beta+2 \alpha+1 \delta$ observations. To perform such a comparison we calculated the ratio of the effective radii $\left(R_{\delta}^{\mathrm{r}}\right)$ derived from the $3 \beta+2 \alpha+1 \delta$ and $3 \beta+2 \alpha$ data sets. Figure 19 shows the profiles of $R_{\delta}^{\mathrm{r}}$ for the same 3 days (the right part being associated with the bottom $x$ axis); a value of 1.0 would mean that the additional input has no impact on the retrieval. Inside the dust layer the ratio is about 1.15 for the measurements taken on 13 and 29 March. On 10 April, the ratio is noisier, but the average is still close to the results obtained for 13 and 29 March. We should mention that the ratio of the particle volumes $R_{\delta}^{\mathrm{V}}$ is very close to $R_{\delta}^{\mathrm{r}}$, so it is not shown in the figure. At present, we are not able to make a definitive conclusion about which data set leads to a more accurate estimation of dust parameters. The dust parameters should be moni-

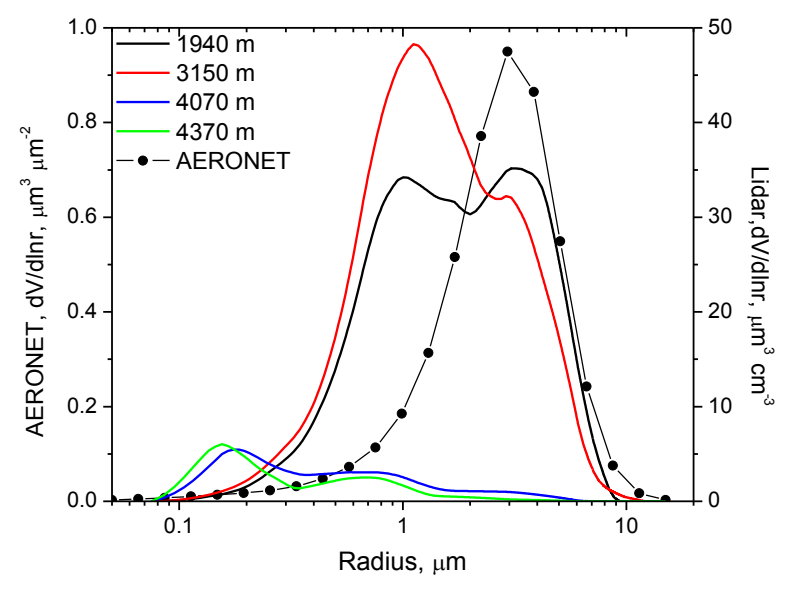

Figure 18. Particle size distributions retrieved from the measurements on 10 April for four height layers of 1940, 3150, 4070, and $4370 \mathrm{~m}$. Symbols show the PSD provided by AERONET on 9 April at 18:00 UTC, inversion level 1.5.

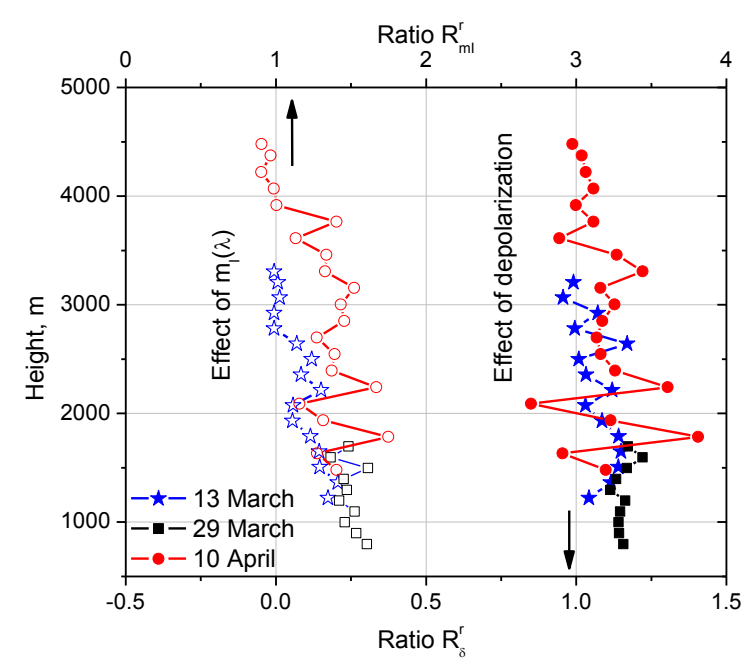

Figure 19. Enhancement of retrieved effective radius due to using the particle depolarization ratio in the input data set $\left(R_{\delta}^{\mathrm{r}}\right)$ and due to accounting for the spectral dependence of the imaginary part of RI $\left(R_{m_{\mathrm{I}}}^{\mathrm{r}}\right)$. Results are shown for the measurements on 13 March, 29 March, and 10 April 2015.

tored independently for this kind of comparison. However, as mentioned in the Introduction, the spheroidal model has difficulty in reproducing high depolarization measurements. As a result, the inversion of $3 \beta+2 \alpha+1 \delta$ dust measurements provides the real part of RI at about 1.45 and the imaginary part below 0.005 , which are lower than expected values based on in situ measurements (Müller et al., 2013). So at present, in the case of pure dust, we prefer to use $3 \beta+2 \alpha$ measurements alone, because they lead to more realistic estimations of the refractive index. Still, the difference between the values retrieved from the two data sets is about $15 \%$, which is lower than the uncertainty of the retrieval which we estimate to be 
of $\sim 30 \%$ for both volume and radius. However, for mixtures of dust with other aerosols, depolarization measurements still should be used in inversion, otherwise the SVF can not be estimated correctly.

The inversion results presented in Figs. 16 and 17 are obtained assuming a spectrally independent refractive index while the imaginary part of CRI of dust is expected to increase in the UV spectral region. To test the effect of a spectrally dependent imaginary part $m_{\mathrm{I}}(\lambda)$ on the retrieval, we now assume that the imaginary parts at 1064 and $532 \mathrm{~nm}$ wavelengths are the same $m_{\mathrm{I}}(532)=m_{\mathrm{I}}(1064)$, while $m_{\mathrm{I}}(355)=4 m_{\mathrm{I}}(532)$. Such an enhancement of $m_{\mathrm{I}}$ at $355 \mathrm{~nm}$ is quite typical for Saharan dust (Ansmann et al., 2011). The $3 \beta+2 \alpha$ measurements for the same 3 days are thus inverted assuming this $m_{\mathrm{I}}(\lambda)$ spectral dependence as described in Veselovskii et al. (2010), while the real part of the refractive index is assumed to be spectrally independent. Figure 19 (left part associated with top $x$ axis) shows profiles of $R_{m_{\mathrm{I}}}^{\mathrm{r}}$, which is the ratio of the effective radii retrieved under the assumption of the spectrally dependent and spectrally independent imaginary parts of RI. Again, the corresponding ratios $R_{m_{\mathrm{I}}}^{\mathrm{V}}$ for the volumes are close to $R_{m_{\mathrm{I}}}^{\mathrm{r}}$ and we do not report them. As expected, the effect of $m_{\mathrm{I}}(\lambda)$ is more pronounced inside the dust layer, and on 29 March and 10 April (days characterized by negative BAE), the value of $R_{m_{\mathrm{I}}}^{\mathrm{r}}$ is up to 1.5. Accounting for $m_{\mathrm{I}}(\lambda)$ dependence also increases the real part of RI, thus on 29 March $m_{\mathrm{R}}$ increases from approximately 1.52 to 1.56 inside the dust layer. These model computations demonstrate that accounting for the spectral dependence of the imaginary part of RI in the dust layers may significantly increase the retrieved values of the effective radius and particle volume. In particular, it may explain smaller radii of the coarse mode particles retrieved from lidar measurements inside the dust layer (Fig. 18) when compared to AERONET results. The effects of spectral dependence of $m_{\mathrm{I}}$ can be to some extent corrected by using $m_{\mathrm{I}}(\lambda)$ model based on in situ measurements and implying it in retrieval algorithms as described in Veselovskii et al. (2010).

\section{Conclusion}

The lidar measurements performed in March-April 2015 during the first phase of the SHADOW campaign in Senegal has provided a significant amount of information about dust particle parameters. The use of rotational Raman scattering in the LILAS for $532 \mathrm{~nm}$ observations improved the $\alpha_{532}$ measurements and, as a result, the calculation of lidar ratio and extinction Ångström exponent were improved as well. The mean values of lidar ratios of pure dust were about $53 \pm 8 \mathrm{sr}$ for both 532 and $355 \mathrm{~nm}$ wavelengths, which agrees with the values observed during SAMUM-1 (Morocco) and SAMUM-2 (Cabo Verde) campaigns. The mean value of the particle depolarization ratio at $532 \mathrm{~nm}$ was $30 \pm 4.5 \%$; however, during strong dust episodes this ratio increased up to $35 \pm 5 \%$, which is also in agreement with the results of the SAMUM campaigns. The backscattering Ångström exponent at $355 / 532 \mathrm{~nm}$ wavelengths during the dust episodes decreased to $\sim-0.7$, while the EAE values, though being negative, were higher than -0.2 . Low values of BAE may be a result of enhanced dust absorption at $355 \mathrm{~nm}$, which should depend on mineralogy at the location of dust origin.

The inversion of $3 \beta+2 \alpha$ measurements to particle microphysics in the case of dust is more challenging than other types of aerosols. The use of pure dust observations somewhat simplifies this task, because the contribution of the particles in the fine mode (which may have different origin) is insignificant. Moreover, in the retrieval of pure dust properties we do not need to consider the mixture of spheres and spheroids and can assume $\mathrm{SVF}=100 \%$. The use of the spheroids model for the inversion of $3 \beta+2 \alpha$ measurements leads to values of effective radius in reasonable agreement with AERONET observations and yields reasonable values of the real part of RI. However, the use of depolarization measurements $(3 \beta+2 \alpha+1 \delta)$ in the inversion for pure dust, which is characterized by a depolarization ratio $\delta_{532}$ exceeding $30 \%$, leads to values of effective radius and volume exceeding the corresponding values obtained from $3 \beta+2 \alpha$ measurements by a factor up to 1.15 . At the same time, the values of $m_{\mathrm{R}}$ are decreased. These issues have already been discussed so at the current time we prefer to not use the depolarization ratio in the input data set for the inversion of dust particle parameters. We hope also that these discussions will stimulate development of the forward model accurately describing polarization properties of laser radiation backscattered by dust particles.

The analysis performed here demonstrates the importance of the spectral dependence of the imaginary part of RI in the UV spectral region. Model simulations demonstrate that including $m_{\mathrm{I}}(\lambda)$ dependence may increase the values of effective radius and volume by a factor as large as 1.5 . Thus, at the moment, dust particle microphysical properties obtained by inversion of lidar measurements may contain significant biases. Further research is needed to develop techniques correcting these biases in order for the uncertainty of the estimates of $r_{\text {eff }}$ and $V$ to remain below $30 \%$, which is a typical value when particles with prevailing fine mode are considered.

In addition to aerosol properties, the LILAS system provided profiles of the water vapor mixing ratio, which, being a conserved quantity, was frequently a convenient tracer that indicated the boundary between dry air masses transported over the continent and moist air masses transported over the ocean. The episodes considered in this paper were characterized mainly by low values of RH and the effects of the particles hygroscopic growth were not considered. Still, we have a significant amount of the measurements in the condition of high RH, accompanied by formation of water and ice clouds near the dust layers. We plan to present these results in a separate publication. 
During phase 1 of SHADOW the aerosols other than dust did not occur in significant amounts inside the height range available for the measurements, so this publication is focused mainly on the pure dust study. However, in phase 2, the episodes of a dust-smoke mixture were observed and such episodes provide opportunity to test the algorithm's ability to profile the layers with different particle types. Such analysis is in progress and will be presented separately.

\section{Data availability}

AERONET data for Dakar instrumentation site are available at http://aeronet.gsfc.nasa.gov/.

Acknowledgements. The authors are very grateful to IRD Dakar (Institut de Recherche pour le Développement) for their welcome and efficient support and also thank the Labex CaPPA for supporting this campaign. The CaPPA project (Chemical and Physical Properties of the Atmosphere) is funded by the French National Research Agency (ANR) through the PIA (Programme d'Investissement d'Avenir) under contract "ANR-11-LABX-000501" and by the Regional Council "Nord-Pas de Calais" and the European Funds for Regional Economic Development (FEDER). Development of lidar retrieval algorithms was partly supported by Russian Science Foundation, (project no. 14-50-00034). The authors gratefully acknowledge the NOAA Air Resources Laboratory (ARL) for the provision of the HYSPLIT transport and dispersion model and/or READY website (http://www.ready.noaa.gov) used in this publication.

Edited by: M. Tesche

\section{References}

AERONET: AERONET data for Dakar instrumentation site, available at: http://aeronet.gsfc.nasa.gov/, last access: January 2016.

Ansmann, A. and Müller, D.: Lidar and atmospheric aerosol particles, in: "Lidar. Range-Resolved Optical Remote Sensing of the Atmosphere", edited by: Weitkamp, C., Springer, New York, USA, 105-141, 2005.

Ansmann, A., Petzold, A., Kandler, K., Tegen, I., Wendisch, M., Müller, D., Weinzierl, B., Müller, T., and Heintzenberg, J.: Saharan Mineral Dust Experiments SAMUM-1 and SAMUM-2: what have we learned?, Tellus, 63B, 403-429, 2011.

Ansmann, A., Seifert, P., Tesche, M., and Wandinger, U.: Profiling of fine and coarse particle mass: case studies of Saharan dust and Eyjafjallajökull/Grimsvötn volcanic plumes, Atmos. Chem. Phys., 12, 9399-9415, doi:10.5194/acp-12-9399-2012, 2012.

Balkanski, Y., Schulz, M., Claquin, T., and Guibert, S.: Reevaluation of Mineral aerosol radiative forcings suggests a better agreement with satellite and AERONET data, Atmos. Chem. Phys., 7, 81-95, doi:10.5194/acp-7-81-2007, 2007.

Binietoglou, I., Basart, S., Alados-Arboledas, L., Amiridis, V., Argyrouli, A., Baars, H., Baldasano, J. M., Balis, D., Belegante,
L., Bravo-Aranda, J. A., Burlizzi, P., Carrasco, V., Chaikovsky, A., Comerón, A., D’Amico, G., Filioglou, M., Granados-Muñoz, M. J., Guerrero-Rascado, J. L., Ilic, L., Kokkalis, P., Maurizi, A., Mona, L., Monti, F., Muñoz-Porcar, C., Nicolae, D., Papayannis, A., Pappalardo, G., Pejanovic, G., Pereira, S. N., Perrone, M. R., Pietruczuk, A., Posyniak, M., Rocadenbosch, F., Rodríguez-Gómez, A., Sicard, M., Siomos, N., Szkop, A., Terradellas, E., Tsekeri, A., Vukovic, A., Wandinger, U., and Wagner, J.: A methodology for investigating dust model performance using synergistic EARLINET/AERONET dust concentration retrievals, Atmos. Meas. Tech., 8, 3577-3600, doi:10.5194/amt-83577-2015, 2015.

Browning, K. A. and Wexler, R.: The determination of kinematic properties of a wind field using Doppler radar, J., Appl. Meteor., 7, 105-113, 1968.

Burton, S. P., Vaughan, M. A., Ferrare, R. A., and Hostetler, C. A.: Separating mixtures of aerosol types in airborne High Spectral Resolution Lidar data, Atmos. Meas. Tech., 7, 419-436, doi:10.5194/amt-7-419-2014, 2014.

De Tomasi, F., Blanco, A., and Perrone, M. R..:Raman lidar monitoring of extinction and backscattering of African dust layers and dust characterization, Appl. Optics, 42, 1699-1709, 2003.

Di Girolamo, P., Summa, D., Bhawar, R., Di Iorio, T., Cacciani, M., Veselovskii, I., Dubovik, O., and Kolgotin, A.: Raman lidar observations of a Saharan dust outbreak event: characterization of the dust optical properties and determination of particle size and microphysical parameters, Atmos. Environ., 50, 66-78, 2012.

Dubovik, O., Sinyuk, A., Lapyonok, T., Holben, B. N., Mishchenko, M., Yang, P., Eck, T. F., Volten, H., Munoz, O., Veihelmann, B., van der Zande, W. J., Leon, J.-F., Sorokin, M., and Slutsker, I.: Application of spheroid models to account for aerosol particle nonsphericity in remote sensing of desert dust, J. Geophys. Res., 111, D11208, doi:10.1029/2005JD006619, 2006.

Esselborn, M., Wirth, M., Fix, A., Weinzierl, B., Rasp, K., Tesche, M., and Petzold, A.: Spatial distribution and optical properties of Saharan dust observed by airborne high spectral resolution lidar during SAMUM 2006, Tellus B, 61, 131-143, 2009.

Formenti, P., Schütz, L., Balkanski, Y., Desboeufs, K., Ebert, M., Kandler, K., Petzold, A., Scheuvens, D., Weinbruch, S., and Zhang, D.: Recent progress in understanding physical and chemical properties of African and Asian mineral dust, Atmos. Chem. Phys., 11, 8231-8256, doi:10.5194/acp-11-8231-2011, 2011.

Formenti, P., Caquineau, S., Desboeufs, K., Klaver, A., Chevaillier, S., Journet, E., and Rajot, J. L.: Mapping the physicochemical properties of mineral dust in western Africa: mineralogical composition, Atmos. Chem. Phys., 14, 10663-10686, doi:10.5194/acp-14-10663-2014, 2014.

Freudenthaler, V., Esselborn, M., Wiegner, M., Heese, B., Tesche, M., Ansmann, A., Müller, D., Althausen, D., Wirth, M., Fix, A., Ehret, G., Knippertz, P., Toledano, C., Gasteiger, J., Garhammer, M., and Seefeldner, M.: Depolarization ratio profiling at severalwavelengths in pure Saharan dust during SAMUM 2006, Tellus, 61B, 165-179, 2009.

Gasteiger, J., Wiegner, M., Groß, S., Freudenthaler, V., Toledano, C., Tesche, M., and Kandler, K.: Modeling lidar-relevant optical properties of complex mineral dust aerosols, Tellus B, 63, 725741, 2011.

Holben, B. N., Eck, T. F., Slutsker, I., Tanre, D., Buis, J. P., Setzer, A., Vermote, E., Reagan, J. A., Kaufman, Y., Nakajima, T., 
Lavenu, F., Jankowiak, I., and Smirnov, A.: AERONET - a federated instrument network and data archive for aerosol characterization, Remote Sens. Environ., 66, 1-16, 1998.

Kandler, K., Lieke, K., Benker, N., Emmel, C., Küpper, M., MüllerEbert,D., Ebert, M., Scheuvens, D., Schladitz, A., Schütz, L., and Weinbruch, S.: Electron microscopy of particles collected at Praia, Cape Verde, during the Saharan Mineral Dust Experiment: Particle chemistry, shape, mixing state and complex refractive index, Tellus, 63B, 475-496, 2011.

Kumer, V.-M., Reuder, J., and Furevik, B. R.: A comparison of LiDAR and radiosonde wind measurements, Energy Procedia, 53, 214-220, 2014.

Li, W. J. and Shao, L. Y.: Observation of nitrate coatings on atmospheric mineral dust particles, Atmos. Chem. Phys., 9, 18631871, doi:10.5194/acp-9-1863-2009, 2009.

Mahowald, N. M., Kloster, S., Engelstaedter, S., Moore, J. K., Mukhopadhyay, S., McConnell, J. R., Albani, S., Doney, S. C., Bhattacharya, A., Curran, M. A. J., Flanner, M. G., Hoffman, F. M., Lawrence, D. M., Lindsay, K., Mayewski, P. A., Neff, J., Rothenberg, D., Thomas, E., Thornton, P. E., and Zender, C. S.: Observed 20th century desert dust variability: impact on climate and biogeochemistry, Atmos. Chem. Phys., 10, 10875-10893, doi:10.5194/acp-10-10875-2010, 2010.

McConnell, C. L., Highwood, E. J., Coe, H., Formenti, P., Anderson, Osborne, B. S., Nava, S., Desboeufs, K., Chen, G., and Harrison, M. A. J.: Seasonal variations of the physical and optical characteristics of Saharan dust: results from the Dust Outflow and Deposition to the Ocean (DODO) experiment, J. Geophys. Res., 113, D14S05, doi:10.1029/2007JD009606, 2008.

Mishchenko, M. I., Travis, L. D., Kahn, R. A., and West, R. A.: Modeling phase functions for dustlike tropospheric aerosols using a mixture of randomly oriented polydisperse spheroids, J. Geophys. Res., 102, 16831-16847, 1997.

Mona, L., Amodeo, A., Pandolfi, M., and Pappalardo, G.: Saharan dust intrusions in the Mediterranean area: three years of Raman lidar measurements, J. Geophys. Res., 111, D16203, doi:10.1029/2005JD006569, 2006.

Müller, D., Wandinger, U., and Ansmann, A.: Microphysical particle parameters from extinction and backscatter lidar data by inversion with regularization: theory, Appl. Optics, 38, 2346-2357, 1999.

Müller, D., Mattis, I., Wandinger, U., Ansmann, A., Althausen, D., and Stohl, A.: Raman lidar observations of aged Siberian and Canadian forest fire smoke in the free troposphere over Germany in 2003: Microphysical particle characterization, J. Geophys. Res., 110, D17201, doi:10.1029/2004JD005756, 2005.

Müller, D., Veselovskii, I., Kolgotin, A., Tesche, M., Ansmann, A., and Dubovik, O.: Vertical profiles of pure dust (SAMUM-1) and mixed smoke-dust plumes (SAMUM-2) inferred from inversion of multiwavelength Raman/polarization lidar data and comparison to AERONET retrievals and in-situ observations, Appl. Optics, 52, 3178-3202, 2013.

Müller, T., Schladitz, A., Massling, A., Kaaden, N., Kandler, K., and Wiedensohler, A.: Spectral absorption coefficients and imaginary parts of refractive indices of Saharan dust during SAMUM-1, Tellus, 61B, 79-95, 2009.

Nisantzi, A., Mamouri, R. E., Ansmann, A., Schuster, G. L., and Hadjimitsis, D. G.: Middle East versus Saharan dust extinction- to-backscatter ratios, Atmos. Chem. Phys., 15, 7071-7084, doi:10.5194/acp-15-7071-2015, 2015.

Papayannis, A., Amiridis, V., Mona, L., Tsaknakis, G., Balis, D., Bösenberg, J., Chaikovski, A., De Tomasi, F., Grigorov, I., Mattis, I., Mitev, V., Müller, D., Nickovic, S., Pérez, C., Pietruczuk, A., Pisani, G., Ravetta, F., Rizi, V., Sicard, M., Trickl, T., Wiegner, M., Gerding, M., Mamouri, R. E., D’Amico, G., and Pappalardo, G.: Systematic lidar observations of Saharan dust over Europe in the frame of EARLINET (2000-2002), J. Geophys. Res., 113, D10204, doi:10.1029/2007JD009028, 2008.

Papayannis, A., Mamouri, R. E., Amiridis, V., Remoundaki, E., Tsaknakis, G., Kokkalis, P., Veselovskii, I., Kolgotin, A., Nenes, A., and Fountoukis, C.: Optical-microphysical properties of Saharan dust aerosols and composition relationship using a multi-wavelength Raman lidar, in situ sensors and modelling: a case study analysis, Atmos. Chem. Phys., 12, 4011-4032, doi:10.5194/acp-12-4011-2012, 2012.

Patterson, E. M., Gillette, D. A., and Stockton, B. H.: Complex Index of Refraction Between 300 and $700 \mathrm{~nm}$ for Saharan Aerosols, J. Geophys. Res. 82, 3153-3160, 1977.

Redelsperger, J.-L., Thorncroft, C. D., Diedhiou, A., Lebel, T., Parker, D. J., and Polcher, J.: African Monsoon Multidisciplinary Analysis: an international research project and field campaign, B. Am. Meteorol. Soc., 87, 1739-1746, 2006.

Reid, J. S. and Maring, H. B: Foreword to special section on the Puerto Rico Dust Experiment (PRIDE), J. Geophys. Res., 108, 8585, doi:10.1029/2003JD003510, 2003.

Ruchith, R. D. and Ernest Raj, P.: Features of nocturnal low level jet (NLLJ) observed over a tropical Indian station using high resolution Doppler wind lidar, J. Atmos. Sol.-Terr. Phy., 123, 113-123, 2015.

Sakai, T., Nagai, T., Nakazato, M., Mano, Y., and Matsumura, T: Ice clouds and Asian dust studied with lidar measurements of particle extinction-to-backscatter ratio, particle depolarization, and water-vapor mixing ratio over Tsukuba, Appl. Optics, 42, 71037116, 2003.

Schwanghart, W. and Schütt, B.: Meteorological causes of Harmattan dust in West Africa, Geomorphology, 95, 412-428, 2008.

Seibert, P., Beyrich, F., Gryning S., Joffre, S., Rasmussen, A., and Tercier, P.: Review and intercomparison of operational methods for the determination of the mixing height, Atmos. Environ., 34, 1001-1027, 2000.

Shimizu, A., Sugimoto, N., Matsui, I., Arao, K., Uno, I., Murayama, T., Kagawa, N., Aoki, K., Uchiyama, A., and Yamazaki, A.: Continuous observations of Asian dust and other aerosols by polarization lidars in China and Japan during ACE-Asia, J. Geophys. Res., 109, D19S17, doi:10.1029/2002JD003253, 2004.

Sokolik, I. N. and Toon, O. B.: Direct radiative forcing by anthropogenic airborne mineral aerosols, Nature, 381, 681-683, 1996.

Stein, A. F., Draxler, R. R., Rolph, G. D., Stunder, B. J. B., Cohen, M. D., and Ngan, F.: NOAA's HYSPLIT atmospheric transport and dispersion modeling system, B. Am. Meteorol. Soc., 96, 2059-2077, 2015.

Tanre, D., Haywood, J., Pelon, J., Leon, J.-F., Chatenet, B., Formenti, P., Francis, P., Goloub, P., Highwood, E. J., and Myhre, G.: Measurements and modeling of the Saharan dust radiative impact: overview of the Saharan Dust Experiment (SHADE), J. Geophys. Res., 108, 8574, doi:10.1029/2002JD003273, 2003. 
Tesche, M., Ansmann, A., Müller, D., Althausen, D., Engelmann, R., Freudenthaler, V., and Groß, S.: Vertically resolved separation of dust and smoke over Cape Verde using multiwavelength Raman and polarization lidars during Saharan Mineral Dust Experiment 2008, J. Geophys. Res., 114, D13202, doi:10.1029/2009JD011862, 2009a.

Tesche, M., Ansmann, A., Müller, D., Althausen, D., Mattis, I., Heese, B., Freudenthaler, V., Wiegner, M., Eseelborn, M., Pisani, G., and Knippertz, P.: Vertical profiling of Saharan dust with Raman lidars and airborne HSRL in southern Morocco during SAMUM, Tellus B, 61, 144-164, doi:10.1111/j.16000889.2008.00390.x, 2009b.

Tesche, M., Groß, S., Ansmann, A., Müller, D., Althausen, D., Freudenthaler, V., and Esselborn, M.: Profiling of Saharan dust and biomass-burning smoke with multiwavelength polarization Raman lidar at Cape Verde, Tellus B, 63, 649-676, doi:10.1111/j.1600-0889.2011.00548.x, 2011.

Thobois, L. and Soderholm, J.: Observing clear air close proximity environment of severe storms, Meteorological Technhology International, 9, 132-135, 2015.

Veselovskii, I., Kolgotin, A., Griaznov, V., Müller, D., Wandinger, U., and Whiteman, D.: Inversion with regularization for the retrieval of tropospheric aerosol parameters from multi-wavelength lidar sounding, Appl. Optics, 41, 3685-3699, 2002.

Veselovskii, I., Dubovik, O., Kolgotin, A., Lapyonok, T., Di Girolamo, P., Summa, D., Whiteman, D. N., Mishchenko, M., and Tanré, D.: Application Of Randomly Oriented Spheroids For Retrieval Of Dust Particle Parameters From Multiwavelength Lidar Measurements, J. Geophys. Res., 115, D21203, doi:10.1029/2010JD014139, 2010.
Veselovskii, I., Whiteman, D. N., Korenskiy, M., Kolgotin, A., Dubovik, O., Perez-Ramirez, D., and Suvorina, A.: Retrieval of spatio-temporal distributions of particle parameters from multiwavelength lidar measurements using the linear estimation technique and comparison with AERONET, Atmos. Meas. Tech., 6, 2671-2682, doi:10.5194/amt-6-2671-2013, 2013.

Veselovskii, I., Whiteman, D. N., Korenskiy, M., Suvorina, A., Kolgotin, A., Lyapustin, A., Wang, Y., Chin, M., Bian, H., Kucsera, T. L., Pérez-Ramírez, D., and Holben, B.: Characterization of forest fire smoke event near Washington, DC in summer 2013 with multi-wavelength lidar, Atmos. Chem. Phys., 15, 16471660, doi:10.5194/acp-15-1647-2015, 2015a.

Veselovskii, I., Whiteman, D. N., Korenskiy, M., Suvorina, A., and Pérez-Ramírez, D.: Use of rotational Raman measurements in multiwavelength aerosol lidar for evaluation of particle backscattering and extinction, Atmos. Meas. Tech., 8, 41114122, doi:10.5194/amt-8-4111-2015, 2015b.

Whiteman, D., Melfi, S., and Ferrare, R.: Raman lidar system for measurement of water vapor and aerosols in the Earth's atmosphere, Appl. Optics, 31, 3068-3082, 1992.

Wiegner, M., Gasteiger, J., Kandler, K., Weinzierl, B., Rasp, K., Esselborn, M., Freudenthaler, V., Heese, B., Toledano, C., Tesche, M., and Althausen, D.: Numerical simulations of optical properties of Saharan dust aerosols with emphasis on lidar applications, Tellus, 61B, 180-194, 2009.

Xie, C., Nishizawa, T., Sugimoto, N., Matsui, I., and Wang, Z.: Characteristics of aerosol optical properties in pollution and Asian dust episodes over Beijing, China, Appl. Optics, 47, 49454951, 2008. 